Document downloaded from:

http://hdl.handle.net/10251/63535

This paper must be cited as:

Albert Gil, FE.; Aleixos Borrás, MN.; Torregrosa Mira, A.; Ortiz Sánchez, MC.; Blasco Ivars, J. (2014). Analysis of the detachment of citrus fruits by vibration using artificial vision. Biosystems Engineering. 119:1-12. doi:10.1016/j.biosystemseng.2013.12.010.

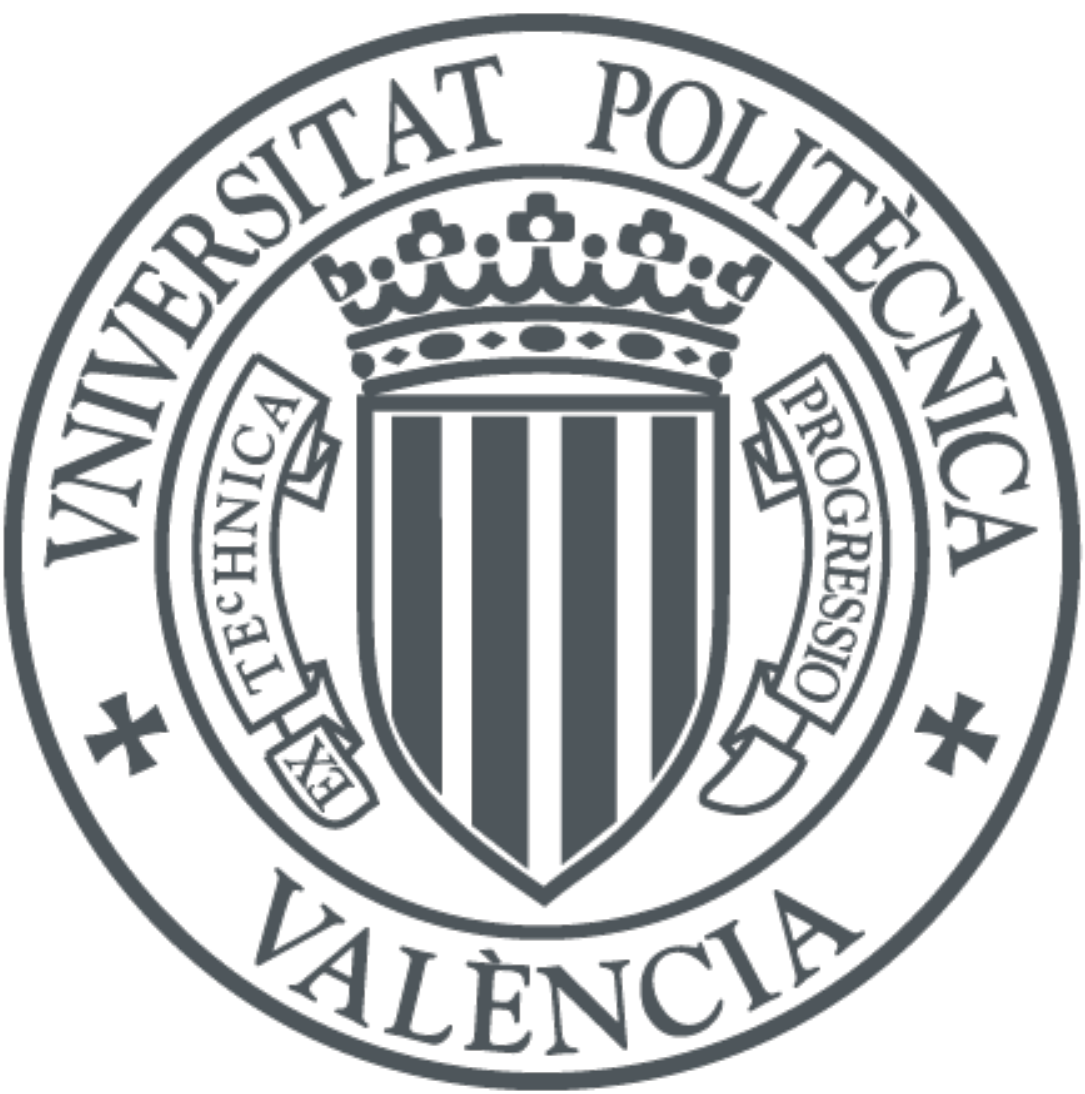

The final publication is available at

http://dx.doi.org/10.1016/j.biosystemseng.2013.12.010

Copyright Elsevier

Additional Information 


\title{
Analysis of the detachment of citrus fruits by vibration using artificial vision
}

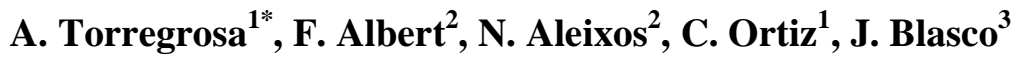 \\ ${ }^{1}$ Dpto. de Ingeniería Rural y Agroalimentaria. Universitat Politècnica de València, Camino de Vera s/n, \\ 46022 Valencia, España. Email: torregro@dmta.upv.es. Tel. + 34 963877291. Corresponding author. \\ ${ }^{2}$ Instituto Interuniversitario de Investigación en Bioingeniería y Tecnología Orientada al Ser Humano. \\ Universitat Politècnica de València. Email: naleixos@labdesign.i3bh.es \\ ${ }^{3}$ Centro de Agroingeniería. Instituto Valenciano de Investigaciones Agrarias (IVIA). Cra. Moncada- \\ Náquera Km 5. 46113 Moncada, Valencia, Spain. Email: blasco_josiva@gva.es
}

\begin{abstract}
The vibratory behaviour of citrus fruits is studied using slow-motion cameras in order to gain a better understanding of the parameters involved in fruit detachment when mechanical harvesting is done using shakers. Single citrus fruits with a small portion of stem were vibrated using strokes from $60 \mathrm{~mm}$ to 180 $\mathrm{mm}$ and frequencies from $3 \mathrm{~Hz}$ to $18 \mathrm{~Hz}$. The movement was recorded at $300 \mathrm{fps}$ and the main parameters considered for fruit detachment were determined through the analysis of the video sequences. Image processing algorithms created for this purpose were applied to the automated estimation of the centroid of the fruit, the angle of the stem-pistil axis, and the position of some selected points in the fruit in each frame of the video sequences to obtain dynamic parameters such as the position, speed and acceleration of the fruit during the movement until it is detached. The signals obtained from the image processing were filtered, providing results in accordance with the calibration systems. In general, results suggest that the inertial forces transmitted to the fruit were lower than the tensile forces required to detach the fruit by pulling it in the stem-pistil direction. The largest peaks were observed using long strokes that required fewer cycles for detachment. On the other hand, short strokes combined with high frequencies needed more cycles, and thus a fatigue phenomenon was present. Short strokes and low frequencies were unable to detach some fruit.
\end{abstract}

Key words: citrus, mechanical harvesting, shaker, image processing, slow motion 


\begin{tabular}{|c|c|}
\hline Nomenclature & \\
\hline$a$ & linear acceleration $\left(\mathrm{m} \mathrm{s}^{-2}\right)$ \\
\hline$\square$ & fruit angular acceleration $\left(\mathrm{rad} \mathrm{s}^{-2}\right)$ \\
\hline$\alpha$ & Angle between stem and fruit equatorial axis (degrees) \\
\hline $\operatorname{Abs}\left(a_{\max }\right)$ & Absolute maximum linear acceleration $\left(\mathrm{m} \mathrm{s}^{-2}\right)$ \\
\hline $\operatorname{Abs}\left(v_{\max }\right)$ & Absolute maximum linear speed $\left(\mathrm{m} \mathrm{s}^{-1}\right)$ \\
\hline 8 & Angle between horizontal and fruit equatorial axis (degrees) \\
\hline CM & centre of mass \\
\hline$\Delta t$ & interval of time between two consecutive frames (1/300 s) \\
\hline$F$ & linear force $(\mathrm{N})$ \\
\hline Fd & traction force $(\mathrm{N})$ \\
\hline$F_{0}$ & Traction force at stem-polar fruit axis angle $0^{\circ}(\mathrm{N})$ \\
\hline$F t$ & tangential force $(\mathrm{N})$ \\
\hline$f$ & frequency $(\mathrm{Hz})$ \\
\hline$f_{h}$ & discrete function of Gaussian filter \\
\hline fps & frame per second \\
\hline$\Phi$ & phase displacement (rad) \\
\hline$h$ & interval between $+w f$ and $-w f$ \\
\hline l & fruit moment of inertia $\left(\mathrm{kg} \cdot \mathrm{m}^{2}\right)$ \\
\hline IVIA & Instituto Valenciano de Investigaciones Agrarias \\
\hline$m$ & fruit mass $(\mathrm{kg})$ \\
\hline$M$ & torque (Nm) \\
\hline$P_{i}$ & position of the centroid in frame $i$ \\
\hline$P_{i-1}$ & position of the centroid in frame $i-1$ \\
\hline$r$ & fruit radius $(\mathrm{m})$ \\
\hline RGB & Red Green Blue \\
\hline SHM & simple harmonic motion \\
\hline $\mathrm{v}$ & linear speed $\left(\mathrm{m} \mathrm{s}^{-1}\right)$ \\
\hline$V_{i}$ & speed measured for frame $i$ \\
\hline$w$ & angular speed $\left(\mathrm{rad} \mathrm{s}^{-1}\right)$ \\
\hline$w f$ & window used for the Gaussian filter \\
\hline $\mathrm{x}$ & half-stroke (m) \\
\hline $\mathrm{x}$ & horizontal coordinate of a point \\
\hline$\left(x f_{i}, y f_{i}\right)$ & smoothed position points \\
\hline y & vertical coordinate of a point \\
\hline
\end{tabular}




\section{Introduction}

Citrus is a very important crop, with a worldwide production of 124 million tons in 2010 (FAO, 2012). Spain is one of the major producers with 5.9 million tons in 2010-11 (Intercitrus, 2012), most of which were to be consumed as fresh fruit. But in recent years, prices have come to a standstill while production costs continue to rise. The implementation of advanced, competitive technology in agriculture allows a higher degree of modernisation of traditional agricultural tasks, thereby resulting in lower production costs and a more rational use of resources, which in turn fosters sustainability and competitiveness among growers. In this regard, harvesting is one of the most important factors affecting the price of citrus fruits in Spain because this task is currently done by hand. Mechanical harvesting is a promising alternative, especially the technique based on detaching the fruit by means of vibratory systems (Sanders, 2005). The mechanical bases of fruit detachment by vibration have been studied since the early 1960s, when the first branch and trunk shakers were constructed (Adrian and Fridley, 1958).

The frequency and amplitude of the shaking movements are some of the most important factors involved in the detachment of these fruits. In theory, natural frequencies cause the highest fruit displacements and therefore the highest detachment percentages are expected, but in practice Adrian and Fridley (1958) and Diener (1968) found that shaking at the natural frequency of most fruit was not very effective, with greater efficiency being achieved using higher frequencies. Similarly, Lenker and Hedden (1968) noted that citrus detachment increases with frequency.

Some theoretical models have been designed to study the phenomenon of fruit detachment. Parchomchuk and Cooke (1972) used a double pendulum to study the behaviour of the fruit-peduncle system, and compared the theoretical results with those obtained from the analysis of recorded images using slowmotion video sequences (160 fps). The model was highly predictive and they concluded that when there is a vertical component in the excitation, resonance happens at around twice the natural frequencies.

In crops such as apples or olives, the peduncle is a structure that is clearly different from the branch into which it is inserted and, hence, in the models defining the system fruit-peduncle, the area to be analysed can be clearly defined. But in the case of citrus fruits, the peduncle has a similar structure to the thin stem where it is inserted, but with a wide range of very different shapes and dimensions, thus making its analysis more difficult. For this reason, experimental trials are necessary to analyse the movement of this fruit.

In a similar line, Torregrosa et al. (2009) studied the influence of frequency on detachment using an orbital trunk shaker that produced an amplitude of $2.5 \mathrm{~cm}$. They tested frequencies of 9,15 and $25 \mathrm{~Hz}$ in 'Orogrande' mandarins and in 'Salustiana' and 'Valencia' oranges, and found that detachment increased with frequency. However, as the frequency increased, so did the defoliation. Ortiz et al. (2013) shook citrus branches in the laboratory to analyse the effect of the frequency, amplitude and shaking time on detachment. They noticed that the point of detachment depended on the stage of maturity of the fruit, the variety and the traction force. High amplitudes and low frequencies achieved a higher percentage of fruit detached with the peduncle, but the effect was not significant so that these parameters could be used to control the detachment point.

Apart from frequency and amplitude, other factors are also important. Rumsey and Barkes (1970) studied several parameters related with detachment in 'Valencia' and 'Navel' oranges and 'Marsh' grapefruits. They measured the traction force necessary to detach the fruit as a function of the direction in which this force was applied, that is, following the calyx-pistil axis or following lines at $45^{\circ}$ and $90^{\circ}$ from the calyxpistil line. They noted that the force decreased as the angle increased. In addition, they observed that a lower rate of detachment was achieved in fruits with longer peduncles, higher amplitudes being more effective. Moreover, they analysed the detachment point of the fruit in the traction tests and found that they were mostly detached without calyx whatever the traction angle. On the other hand, in torsion tests, most of the fruits were detached with calyx and the rest with peduncle, while in the vibratory tests the fruit detached with calyx decreased. Alper and Foux (1976) analysed the mechanical resistance of 'Shamouti' oranges to axial, flexion, torsion and combined forces. They separated the branches from the tree and performed the tests under laboratory conditions and found that axial strength was the main component to detach the fruit. When the force was applied with some inclination with respect to the calyx-bottom axis, the force required decreased to less than half. On the other hand, peduncle flexion and torsion had only a minor influence on detachment.

One problem in research about the fundamentals of fruit detachment is that most work has been based on theoretical models that are compared with detachment percentage, detachment point, etc., to measure traction forces in quasi-static tests, but few works measure the real forces that occur in the fruit during 
shaking. Several attempts have been made, however. Garman et al. (1972) performed some tests with an apple fitted with a load cell. The drawback of this method is that devices like accelerometers or load cells placed directly on the fruit can alter their physical properties and hence distort the results. An alternative is the use of slow-motion cameras capable of recording video-sequences at a high rate of frames per second, which allow the movement of the fruit under shaking to be reproduced in detail.

One of the problems of applying visual systems to study the movement of the fruit is the large number of parameters involved in the detachment mechanism, which makes the task of analysing the sequences captured by the cameras time consuming and tedious if they have to be analysed visually frame by frame by an operator. For instance, a sequence of 4 seconds recorded at a rate of 300 frames per second produces a total of 1200 frames that have to be analysed individually. In addition, a factor of subjectivity is introduced because different operators can apply different criteria to measure the parameters and such a repetitive task can bias the analysis as the fatigue of the operator increases. Therefore, the development of fast, accurate and objective tools is required to optimise this process. A potential alternative is to develop systems based on automatic image analysis technology, which are already being used in other areas of agriculture (Cubero et al., 2011; Lorente et al., 2012), including applications in the field. For instance, Mizushima and Lu (2010) and Vidal et al. (2012) developed systems for the pre-sorting of apples and oranges respectively in the field. Jimenez et al. (2000) used machine vision to locate fruit on the trees. Furthermore, Qiao et al. (2005) used this technology combined with a mobile grading robot to map the yield and estimate its quality in the field. Cubero et al. (2013) proposed an inspection system mounted on a mobile platform to inspect citrus fruits in the field as they were being harvested. Other examples of the use of machine vision technology operating in the field are those applied to automate the harvesting task. For instance, Kondo et al. (2005) and Guo et al. (2008) used this technology for robotic strawberry harvesting, Ling et al. (2004) for tomatoes, Edan et al. (2000) for melons, Muscato et al. (2005) for oranges and Van Henten et al. (2000) for cucumbers, among others.

In this work, the movement described by citrus fruit when shaken has been analysed using high-speed cameras and image-processing algorithms to obtain a better understanding of the mechanisms involved in fruit detachment, and thereby optimise the design parameters of machines for automatic citrus harvesting.

\section{Objectives}

This work has two main objectives:

- to develop a tool, based on the analysis of the video sequences of the shaken fruit acquired by slow-motion cameras, that is capable of obtaining robust and accurate information about the movement of the fruit, such as the trajectory, the angles or the accelerations suffered while vibrating.

- to use this information to study the behaviour of the fruit under the shaking movement using artificial vision techniques in order to understand and optimise the mechanisms involved in fruit detachment.

\section{Material and methods}

This section shows the development of a tool based on computer vision that can be used for the analysis of video sequences of the fruit while it is being vibrated. It also outlines the experiments carried out using this tool to study the mechanisms involved in the detachment of the fruit.

\subsection{Development of the computer vision system for shaking analysis}

\subsubsection{Acquisition of the video sequences}

The samples were shaken by means of a laboratory unidirectional shaker device (Figure 1) with a continuously adjustable rotational speed between $0-20 \mathrm{~Hz}$ and 4 possible strokes: 60, 100, 140 and 180 $\mathrm{mm}$. The stems of the fruit were attached to the shaker by a drill chuck.

A high-speed digital colour video camera CASIO model EX-F1 was used to record the movement of different fruits at a rate of 300 frames per second. Each image had a size of 512 x 384 pixels. The fruit was placed in front of a black background under natural lighting. Different video sequences were acquired at different times of the day using a diffuse reflecting surface to make the light more uniform and to minimise the variability of the natural light. Figure 1 shows the set-up used in the experiments. The fruit used to develop and tune the image processing algorithms were 'Valencia' oranges, 'Nova' mandarins and 'Eureka' lemons. This fruit was different from those used in the experiments to study the movement of the fruit. 


\subsubsection{Fruit identification}

Figure 1. Vision and shaker system

The segmentation of the images of the video sequences consisted of classifying the RGB values of each pixel as belonging to one of the predefined classes (background, fruit, stem, etc.). This classification was performed using a Bayesian discriminant analysis (Chou \& Brown, 1990; Blasco et al., 2009). A set of neighbouring pixels of the same class were taken to be an object. The largest object in the image was considered to be the fruit, while small objects found in the image were removed. The contour of each object was extracted by means of the chain code described by Freeman (1961) and the centre of mass $(\mathrm{CM})$ of the objects (centroid) were calculated using the boundary information, that is, by accumulating the $\mathrm{X}$ and $\mathrm{Y}$ coordinates and dividing them by the number of contour points (the centroids will be used later as centres of mass).

\subsubsection{Estimation of the parameters of the movement}

In order to analyse the movement of the fruit, several parameters, which are described in the following subsections, were estimated from each frame in the video sequences:

- Centroid and axes of the fruit.

- Linear speed and acceleration.

- Angles.

- Dynamic parameters of the fruit.

\section{Important axes}

The polar axis of the fruit is the line from the stem to the style of the fruit, and the equatorial axis of the fruit is the line that is perpendicular to the polar axis and crosses the centroid of the fruit. In order to avoid the error of mistakenly taking the equatorial axis as the projected moment of inertia of the fruit object (green line in Fig. 2) instead of the real equatorial axis (yellow line in Fig.2), two labels were placed in line with the equatorial axis. This is very important in order to properly relate the forces involved in the fruit detachment with the rotation in the movement. Finally, the stem axis is calculated as the smallest moment of inertia of the stem object found in the image, that is, the major axis of the stem, since it is a cue position when detaching fruit. Figure 3 shows the movements experienced by a fruit when it is shaken and the angles between the axes of both fruit and stem objects after image processing.

Figure 2. Left: Initial position of the fruit, where the projected equatorial diameter of the quasi-spherical object matches the real one. Right: Position of the fruit, where the projected equatorial diameter (in green) does not match the real one (in yellow indicated by the two labels)

Figure 3. Left: Movements experienced by the fruit (yellow arrow for spinning motion, blue arrow for pendulum motion and green arrows for displacements of the fruit centroid); main axes of the fruit and peduncle are also depicted. Centre and right: 'Equatorial diameter fruit/stem' angle and 'Equatorial diameter fruit/horizontal axis' angle in two different sequences

\section{Linear speed and acceleration}

The movement of the fruit was obtained from the location of the centroid coordinates of the fruit throughout the sequence. However, problems arise when velocities and accelerations were estimated from these positions, since they move between images in discrete displacements and therefore the influence of noise has a great impact on the calculation of these variables:

$$
V_{i}=\left(P_{i}-P_{i-1}\right) / \Delta t
$$

where $V_{i}$ is the speed measured for frame $i$ calculated from the Euclidean distance between the positions $P$ of the centroid in the frames $(i-1)$ and $i$, and $\Delta t$ is the interval of time between two consecutive frames 
$(1 / 300 \mathrm{~s})$. Taking into account the fact that the resolution of the images in the video is relatively poor $\left(0.56 \mathrm{~mm} \mathrm{pixel}^{-1}\right)$, an error of just one pixel in the estimated position of the centroid means a variation in the measured speed of the fruit of $168 \mathrm{~mm} \mathrm{~s}^{-1}$. These errors are even larger when acceleration is calculated. For this reason, a good filtering of the signals is of vital importance to obtain reliable velocity and acceleration values. A Gaussian filter (low-pass filter) was used to reduce these errors. The discrete function of the Gaussian filter $f_{h}$ was:

$$
f_{h}=e^{-\frac{h^{2}}{2 w f^{2}}}, h \in[-w f, w f]
$$

where $w f$ is the window used for the filter that was set empirically in this case to a value of 5 .

The smoothed position points $\left(x f_{i}, y f_{i}\right)$ were then obtained by discrete convolution of the points that were measured with the Gaussian filter, each of them being divided by the sum of the filter values:

$$
x f_{i}=\frac{\sum_{h=-w f}^{w f} f_{h} \cdot x_{i+h}}{\sum_{h=-w f}^{w f} f_{h}}, y f_{i}=\frac{\sum_{h=-w f}^{w f} f_{h} \cdot y_{i+h}}{\sum_{h=-w f}^{w f} f_{h}}
$$

The process to obtain the accelerations and speed of the fruit is shown in Figure 4. Fig.4a shows the trajectory followed by the centroid of the fruit in green, while Figures $4 b-4 d$ show the different signals obtained for linear trajectory, speed and acceleration.

Figure 4. a) trajectory followed by the centroid of the fruit; b) evolution of the $X$ coordinate of the centroid through the different frames; c) evolution of the estimated speed; d) evolution of the estimated acceleration (for all the images, the red signal shows the original values and the blue signals the data after filtering).

\section{Angles}

For each frame, the angle between the stem axis and the polar axis of the fruit was calculated in order to know how the different parameters involved in the shaking affect the pendulum movement of the fruit, especially at the ends of the movement, in the stem breakdown. Figure 5 shows the evolution of the angles for the trajectory of the fruit shown in Figure 4. When both axes are aligned (initial position) the angle should be zero. The angle has also been filtered as explained.

Figure 5. Evolution of the filtered angle between the stem and polar axis of the fruit

\section{Dynamic parameters of the fruit}

The data obtained for the parameters of the movement of the fruit from the video analysis, the movements of translation, rotation and changes in the stem-fruit angle were calculated as follows:

Translation displacements give rise to linear forces that can be obtained from the linear accelerations and the fruit mass. These forces were calculated as related to the centre of mass $(\mathrm{CM})$ of the fruit according to:

$$
F=m a
$$

where $F$ is the force $(\mathrm{N}), m$ is the fruit mass $(\mathrm{kg})$ and $a$ is the CM acceleration $\left(\mathrm{m} \mathrm{s}^{-2}\right)$.

The torque originated by the rotational movement was calculated supposing fruits were spherical and according to:

$$
M=I \square=2 / 5 m r^{2} \square
$$

where $M$ is the torque related to the $\mathrm{CM}(\mathrm{Nm}), I$ is the moment of inertia of the fruit in relation to the centre of mass, $r$ is the radius of the fruit $(\mathrm{m})$ and $\square$ is the angular acceleration of the fruit $\left(\mathrm{s}^{-2}\right)$. 
In order to compare this torque with the translational forces, the tangential $(F t)$ equivalent force to produce the moment was calculated:

$$
F t=M / r
$$

Moreover, the stem-fruit angle $(\alpha)$ was measured and its maximum bending was calculated throughout the whole movement of the fruit over time. The flowchart of the process of image analysis can be seen in Figure 6.

Figure 6. Flowchart of the processes of image analysis and subsequent calculation of dynamic parameters.

\subsection{Dynamic tests}

\subsubsection{Laboratory shaker characterisation}

Since the movement of the shaker used to vibrate the fruits is planar and is provided by a slider-crank mechanism, it can be assumed to be a simple harmonic motion (SHM) and therefore the theoretical accelerations can be obtained using the following formulas (Young \& Freedman, 2006):

$$
\begin{aligned}
& x=X \sin (w t+\Phi) \\
& v=d x / d t=w X \cos (w t+\Phi) \\
& a=d v / d t=-w^{2} X \sin (w t+\Phi)
\end{aligned}
$$

In the case of the maximum absolute values:

$$
\begin{aligned}
& \operatorname{Abs}\left(v_{\max }\right)=w X=2 \pi f X \\
& \operatorname{Abs}\left(a_{\max }\right)=w^{2} X=(2 \pi f)^{2} X
\end{aligned}
$$

where $t$ is time (s); $x$ is the position $(\mathrm{m}), X$ is half of the stroke $(\mathrm{m}), w$ is the angular speed $\left(\mathrm{rad} \mathrm{s}^{-1}\right), f$ is the frequency $(\mathrm{Hz}), \Phi$ is the phase displacement $(\mathrm{rad}), v$ is the linear speed $\left(\mathrm{m} \mathrm{s}^{-1}\right)$, and $a$ is the linear acceleration $\left(\mathrm{m} \mathrm{s}^{-2}\right)$.

The theoretical values obtained from the parameters adjusted for different strokes and frequencies were compared with those obtained from the video analysis.

\subsubsection{Experiments}

A set of experiments were conducted to study the movement of the fruit with this tool. Single fruit without apparent defects and uniform colour were used for the tests. The fruit were collected from the field collection of the Citrus Germplasm Bank at the IVIA (Navarro et al., 2002) with a stem of about 30 $\mathrm{cm}$ in length. Some leaves in the samples used for the vibration tests were removed in order not to hide the fruit during the movement and thus obtain good video recordings for the image analysis. In addition, the mass and diameter of all the fruits were measured.

Some key positions of the fruits were selected and labelled with colour codes in order to make it easier for the vision system to track the movement and thus facilitate the calculation of the bending of the fruit with respect to the stem. This was necessary because the fruits were quasi-spherical and the main axes obtained from the moments of inertia were not stable enough to track the movement when shaking. The movements of the fruit under different strokes and frequencies were recorded to accomplish several tests. The dynamic parameters were obtained using the automatic vision system and visually by an expert who analysed them frame by frame in order to compare both results. This visual analysis took approximately six hours per video but the time depended strongly on the number of frames.

\section{Vibration transmission efficiency}

The theoretical accelerations of the laboratory shaker were compared with the accelerations of the fruit centre. The ratio between both accelerations was used to measure the shaking transmission efficiency. The combinations of two theoretical strokes $(60 \mathrm{~mm}$ and $100 \mathrm{~mm})$ and two frequencies $(9 \mathrm{~Hz}$ and $18 \mathrm{~Hz})$ were tested using three 'Valencia' oranges.

\section{Fruit movement analysis}

A total of 18 'Marisol' mandarins, 40 'Nova' mandarins and 12 'Valencia' oranges were shaken with strokes of $60 \mathrm{~mm}, 100 \mathrm{~mm}$ and $180 \mathrm{~mm}$ and frequencies ranging from $3.2 \mathrm{~Hz}$ to $17.4 \mathrm{~Hz}$.

\section{Effect of stroke and frequency}


The effect of stroke, frequency and their combinations on the forces and bending angles was analysed using 40 'Nova' mandarins. All the combinations between strokes of $60 \mathrm{~mm}$ and $100 \mathrm{~mm}$ and frequencies of $4.1 \mathrm{~Hz}, 9.3 \mathrm{~Hz}$ and $14.0 \mathrm{~Hz}$ were analysed. Additionally, the combination of a stroke of $180 \mathrm{~mm}$ and a frequency of $4.1 \mathrm{~Hz}$ was tested. The combination of this stroke with higher frequencies was not tested because it was observed in preliminary tests that all the fruits were detached. Regression analysis was performed to relate the effect of frequency on the linear force $(F)$ and bending angle $(\alpha)$.

\subsection{Quasi-static traction tests}

The inertial forces estimated from the analysis of the videos were compared to the ones measured in the quasi-static traction detachment tests. To do this, the traction force of 'Valencia' and 'Navel Lane Late' oranges and 'Eureka' lemons was measured by pulling the stems of the fruit in the direction of the calyxpistil axis $\left(0^{\circ}\right)$ and also at $45^{\circ}$ and $90^{\circ}$ to this axis, using a traction-test machine (Ibertest, model IBTH 2730 , www.ibertest.es), with a constant speed of $1.67 \mathrm{~m} \mathrm{~s}^{-1}$. The mass and diameter of all the fruits were also measured.

Figure 7. 'Navel Lane Late' orange during the quasi-static traction test at a traction angle of $0^{\circ}$

\subsection{Fruit used in the trials}

The main parameters of the fruit used in the trials are summarised in Table 1.

Table 1. Parameters measured in the fruit (average values and standard deviation between brackets)

\begin{tabular}{|c|c|c|c|c|c|c|c|c|}
\hline Variety & $\begin{array}{c}\text { Fruit } \\
\text { mass } \\
(\mathrm{g})\end{array}$ & $\begin{array}{l}\text { Equatorial } \\
\text { diameter } \\
(\mathrm{mm})\end{array}$ & $\begin{array}{c}\text { Polar } \\
\text { diameter } \\
(\mathbf{m m})\end{array}$ & $\begin{array}{l}\text { Peduncle } \\
\text { diameter } \\
(\mathbf{m m})\end{array}$ & ${ }^{\circ}$ Brix & $\begin{array}{c}\text { Maturity } \\
\text { Index }^{\mathbf{a}}\end{array}$ & $\begin{array}{l}\text { Traction } \\
\text { Force } \\
\text { (N) }\end{array}$ & $\begin{array}{c}\text { Harvesting } \\
\text { date }\end{array}$ \\
\hline Eureka $^{1}$ & $218(87)$ & 70.7 (10) & $92(13)$ & $2.9(0.3)$ & 6.6 & 1.24 & $118(40)$ & $\begin{array}{r}\text { 23rd March } \\
2011\end{array}$ \\
\hline $\begin{array}{l}\text { Navel } \\
\text { Lane } \\
\text { Late }^{1}\end{array}$ & $280(66)$ & $81(6)$ & 77 (7) & $3.5(0.4)$ & 11.8 & 8.47 & $71(6.0)$ & $\begin{array}{r}\text { 31st March } \\
2011\end{array}$ \\
\hline Valencia $^{1}$ & $181(31)$ & $72(5)$ & $68(5)$ & $3.0(0.2)$ & 11.8 & 4.8 & $45(23)$ & $\begin{array}{r}25 \text { th March } \\
2011\end{array}$ \\
\hline Marisol $^{2}$ & $95(25)$ & $58(4)$ & $52(5)$ & $4.2(0.8)$ & 9.8 & 5.5 & $39(9.2)$ & $\begin{array}{r}\text { 5th Oct } \\
2011\end{array}$ \\
\hline Nova $^{2}$ & $103(25)$ & $62(7)$ & $50(4)$ & $3.2(0.5)$ & 12.2 & 9.2 & $63(9.8)$ & $\begin{array}{r}24 \text { th Nov } \\
2011\end{array}$ \\
\hline Valencia $^{2}$ & $151(36)$ & $63(7)$ & $69(4)$ & $2.7(0.2)$ & 9.3 & 7.5 & $58(12.3)$ & $\begin{array}{r}\text { 9th May } \\
2011\end{array}$ \\
\hline
\end{tabular}

\section{Results and discussion}

\subsection{Quasi-static traction detachment tests}

The detachment force of the fruit was measured by pulling from the stems of the fruits in the calyx-pistil direction $\left(0^{\circ}\right)$ and also at $45^{\circ}$ and $90^{\circ}$ degrees from that axis. It was observed that the traction force needed to detach the fruit decreased as the angle increased with respect to the straight line running between calyx-pistil. On average, the forces needed to detach the fruit were $66 \%$ and $41 \%$, at $45^{\circ}$ and $90^{\circ}$ respectively, of the force required at $0^{\circ}$ (Table 2), which is in accordance with Alper and Foux (1976). 
Table 2. Traction force needed to detach the fruits at three different angles in the quasi-static tests

\begin{tabular}{|c|c|c|c|c|}
\hline & Level & \multicolumn{2}{|c|}{$F d(\mathbf{N})$} & $F d / F_{0}$ \\
\hline & & average $^{1}$ & $\mathrm{sd}$ & \\
\hline \multirow{3}{*}{ Angle (degrees) } & $0^{0}$ & $92^{\mathrm{a}}$ & 32 & 1.00 \\
\hline & $45^{0}$ & $61^{b}$ & 21 & 0.66 \\
\hline & $90^{\circ}$ & $38^{c}$ & 15 & 0.41 \\
\hline \multirow{3}{*}{ Variety } & 'Eureka' lemon & $76^{a}$ & 45 & \\
\hline & 'Navel Lane Late' orange & $68^{a}$ & 28 & \\
\hline & 'Valencia' orange & $49^{b}$ & 23 & \\
\hline \multirow{9}{*}{ Angle $x$ Variety } & $0^{0} \times$ Eureka & 120 & 41 & 1 \\
\hline & $0^{0} \times$ Navel Lane Late & 93 & 26 & 1 \\
\hline & $0^{0} \times$ Valencia & 72 & 17 & 1 \\
\hline & $45^{0} \times$ Eureka & 73 & 25 & 0.60 \\
\hline & $45^{0} \times$ Navel Lane Late & 65 & 20 & 0.70 \\
\hline & $45^{0} \times$ Valencia & 47 & 13 & 0.65 \\
\hline & $90^{\circ} \times$ Eureka & 36 & 13 & 0.30 \\
\hline & $90^{0}$ x Navel Lane Late & 46 & 14 & 0.49 \\
\hline & $90^{\circ} \times$ Valencia & 27 & 10 & 0.37 \\
\hline \multicolumn{5}{|c|}{$F d$, traction force; $F_{o}$, traction force at angle $0^{\circ} ;$ sd, standard deviation } \\
\hline \multicolumn{5}{|c|}{${ }^{1}$ Different letters denote statistically significant differences. Method: $95 \%$ LSD } \\
\hline
\end{tabular}

On the other hand, the traction force necessary to break the stems by applying a force in a straight line was also measured in 'Valencia' oranges. Values obtained ranged between 52 and 170 N. No relationship was found between the diameter of the stem and the traction force.

\subsection{Dynamic tests}

\subsubsection{Laboratory shaker movement analysis}

The real accelerations were calculated from the analysis of the frames in the video sequence according to the methods explained. These accelerations were compared with the theoretical parameters of an SHM, very close values being obtained (Table 3 ).

Table 3. Theoretical and estimated accelerations obtained from the analysis of the videos

\begin{tabular}{|c|c|c|c|}
\hline Stroke $(2 X), \mathrm{mm}$ & Frequency $f, \mathrm{~Hz}$ & $\begin{array}{c}\text { Theoretical acceleration } \\
\text { SHM } \operatorname{Abs}\left(a_{\max }\right) \mathrm{m} \mathrm{s}^{-2}\end{array}$ & $\begin{array}{c}\text { Real acceleration } \\
\operatorname{Abs}\left(a_{\max }\right), \mathrm{m} \mathrm{s}^{-2}\end{array}$ \\
\hline 63 & 9.4 & 109 & 107 \\
\hline 100 & 8.8 & 152 & 163 \\
\hline 79 & 17.4 & 471 & 488 \\
\hline
\end{tabular}

\subsubsection{Vibration transmission efficiency}

The results obtained are shown in Table 4. The theoretical accelerations of the laboratory shaker were compared with those observed for the fruit centre in the videos and the ratio between both accelerations was used to measure the efficiency of the shaking transmission. The lower frequencies $(8.8 \mathrm{~Hz}$ and 9.4 $\mathrm{Hz}$ ) gave a ratio of 0.71 and 0.72 regardless of the stroke, but the ratio was lower in the case of the highest frequency $(17.4 \mathrm{~Hz})$, descending to only 0.14 . This means that higher frequencies were more inefficient in terms of energy transmission. On the other hand, it was also noted that the tangential forces (the ones that originated in the fruit as a consequence of a rotational movement with respect to the fruit centre in the image plane) were lower than the linear forces in all cases. The detachment measured in terms of time (s) was similar for the combinations using low frequency and long stroke or short stroke and high frequency, and about three times lower than that achieved for the combination of short stroke with low frequency. In terms of cycles, the longer stroke was the most efficient. 
Table 4. Comparison of accelerations and forces between a theoretical sinus wave and the fruit centre of 'Valencia' oranges

\begin{tabular}{|c|c|c|c|c|c|c|c|c|c|c|c|}
\hline \multirow{2}{*}{$\begin{array}{c}\text { Stroke } \\
\text { m }\end{array}$} & \multirow{2}{*}{$\begin{array}{c}\text { Freq } \\
\mathrm{Hz}\end{array}$} & \multicolumn{3}{|c|}{ Acceleration, $\mathrm{m} \mathrm{s}^{-2}$} & \multicolumn{2}{|c|}{ Linear forces, $\mathbf{N}$} & \multirow{2}{*}{$\begin{array}{c}\begin{array}{c}\text { Tan. } \\
\text { force, } \\
\mathbf{N}\end{array} \\
\text { Fruit }\end{array}$} & \multicolumn{2}{|c|}{$\begin{array}{l}\text { Fruit traction } \\
\quad \text { force, } \mathbf{N}\end{array}$} & \multicolumn{2}{|c|}{ Detachment } \\
\hline & & $\begin{array}{l}\text { Theo- } \\
\text { retical }\end{array}$ & $\begin{array}{c}\text { Ob- } \\
\text { served }\end{array}$ & Ratio & $\begin{array}{l}\text { Theo- } \\
\text { retical }\end{array}$ & $\begin{array}{c}\text { Ob- } \\
\text { served }\end{array}$ & & $\mathbf{0}^{\circ}$ & $90^{\circ}$ & time, $s$ & $\begin{array}{c}\text { cycles, } \\
\text { num. }\end{array}$ \\
\hline 0.100 & 8.8 & 152 & 108 & 0.71 & 24 & 17 & 10 & 58 & 19 & 0.503 & 4.4 \\
\hline 0.063 & 9.4 & 109 & 78 & 0.72 & 14 & 10 & 8 & 58 & 19 & 1.655 & 15.5 \\
\hline 0.079 & 17.4 & 471 & 68 & 0.14 & 75 & 11 & 9 & 58 & 19 & 0.495 & 8.6 \\
\hline
\end{tabular}

\subsubsection{Analysis of the movement of the fruit}

The movement of 70 fruits was analysed. The main parameters of the fruit used in these trials are summarised in Table 1. The inertial forces estimated from the analysis of the videos (Table 5) were compared to the ones measured in the quasi-static traction detachment test.

Table 5. Inertial forces estimated from the videos of the shaken fruits

\begin{tabular}{|c|c|c|c|c|c|c|c|c|c|}
\hline Variety & $\begin{array}{c}\text { stroke } \\
(\mathbf{m m})\end{array}$ & $\begin{array}{c}\mathbf{f} \\
(\mathbf{H z})\end{array}$ & $\begin{array}{c}\text { Linear } \\
\mathbf{f o r c e} \\
(\mathbf{N})\end{array}$ & $\begin{array}{c}\text { Fruit } \\
\text { rotation } \\
\left(\boldsymbol{\beta} \boldsymbol{,}^{\circ}\right)\end{array}$ & $\begin{array}{c}\text { Fruit-stem } \\
\text { angle } \\
\left(\boldsymbol{\alpha} \boldsymbol{,}^{\circ}\right)\end{array}$ & $\begin{array}{c}\text { Tan. force } \\
(\mathbf{N})\end{array}$ & $\begin{array}{c}\text { Time to } \\
\text { detach } \\
(\mathbf{s})\end{array}$ & $\begin{array}{c}\text { Cycles to } \\
\text { detach } \\
(\mathbf{N u m})\end{array}$ & $\begin{array}{c}\text { Repeti- } \\
\text { tions } \\
(\mathbf{N u m})\end{array}$ \\
\hline Marisol & 60 & 4.7 & 7 & 66 & 53 & 7 & 2.37 & 11.1 & 4 \\
\hline Marisol & 60 & 9.5 & 11 & 87 & 112 & 7 & 1.34 & 12.7 & 5 \\
\hline Marisol & 60 & 13.6 & 9 & 65 & 73 & 7 & 0.33 & 4.3 & 5 \\
\hline Marisol & 180 & 3.1 & 10 & 87 & 83 & 11 & 0.54 & 1.67 & 4 \\
\hline Nova & 60 & 4.1 & 4.3 & 46 & 45 & 1.8 & 17.45 & 71.5 & 5 \\
\hline Nova & 60 & 9.3 & 6.0 & 58 & 125 & 4.0 & 6.18 & 57.5 & 6 \\
\hline Nova & 60 & 14.0 & 14.2 & 79 & 146 & 4.5 & 0.94 & 13.2 & 6 \\
\hline Nova & 100 & 4.1 & 9.6 & 101 & 102 & 3.2 & 3.94 & 16.2 & 6 \\
\hline Nova & 100 & 9.3 & 16.6 & 102 & 104 & 5.7 & 0.29 & 2.7 & 6 \\
\hline Nova & 100 & 14.0 & 9.0 & 85 & 119 & 7.9 & 0.30 & 4.2 & 6 \\
\hline Nova & 180 & 4.1 & 9.6 & 128 & 139 & 4.9 & 1.48 & 6.1 & 5 \\
\hline Valencia & 60 & 9.4 & 10 & 96 & 104 & 8 & 1.66 & 15.6 & 4 \\
\hline Valencia & 60 & 17.4 & 11 & 104 & 83 & 9 & 0.50 & 8.7 & 4 \\
\hline Valencia & 100 & 8.8 & 17 & 129 & 134 & 10 & 0.50 & 4.4 & 4 \\
\hline
\end{tabular}

'Marisol' mandarins need a detachment traction force of $39 \mathrm{~N}$ (Table 1), but the inertial forces experienced by the fruit were in the range of $7 \mathrm{~N}$ to $11 \mathrm{~N}$, which were $23 \%$ of the traction force. In all the combinations of stroke and frequency tested, the fruit-peduncle axis bent more than $53^{\circ}$, in some cases going beyond $90^{\circ}$. Hence the axial forces of the peduncles were applied with large angles with respect to the original position of the fruit, and thus it can be assumed that the inertial forces will be applied at wide angles, where the traction force can be reduced by around $50 \%$. Despite this assumption, the angular traction force must be in the order of $20 \mathrm{~N}$, which is still around twice the maximal inertial force. The results obtained are in agreement with the fact that no fruit was detached in the first cycle, several cycles being necessary in all the cases to achieve detachment. This means that it was necessary to fatigue the fruit-stem-stalk junctions prior to detachment of the fruit.

The same pattern was observed in 'Valencia' oranges, in which the inertial forces were three to six times lower than the traction force. The largest peaks in the force were observed with the longer strokes that 
required fewer cycles for detachment. On the other hand, short strokes and low frequencies were unable to detach some fruits.

The same pattern was found in 'Nova' mandarins, with linear $(4.3 \mathrm{~N}$ to $16.6 \mathrm{~N})$ and tangential forces $(1.8$ to $7.9 \mathrm{~N})$ that were quite a lot lower than the traction force $(63 \mathrm{~N})$.

The detachment point in the fruit-stem-stalk system has been widely studied in fruits like apples (Parchomchuk \& Cooke, 1972), cherries (Zhang, 2012) and olives (López \& Gracia, 1979; Tsatsarelis, 1987 ) in order to control that point by means of controlled vibration parameters like stroke and frequency. In the case of citrus, however, the shape, number of junctions and the relative dimensions of fruits, stems and stalks are so variable that it is very difficult to predict the behaviour of the system.

\subsubsection{Effect of stroke and frequency}

Stroke and frequency are the two most important parameters in fruit detachment by shaking. As there were important interactions between the strokes and frequencies tested, the results were analysed for any combination. The resulting forces and angles obtained are summarised in Table 6.

Table 6. Parameters measured in the fruits for the different stroke and frequency applied to 'Nova' mandarins: translational force $(F)$, tangential force $(F t)$ and fruit-peduncle bending angle $(\alpha)$

\begin{tabular}{|c|c|c|c|c|c|c|c|c|c|c|c|c|}
\hline & \multicolumn{3}{|c|}{$F(\mathrm{~N})$} & \multicolumn{3}{|c|}{$\alpha\left(^{\circ}\right)$} & \multicolumn{3}{|c|}{$F t(\mathrm{~N})$} & \multicolumn{3}{|c|}{ Ratio $F / F t$} \\
\hline & $4.1 \mathrm{~Hz}$ & $9.3 \mathrm{~Hz}$ & $14.0 \mathrm{~Hz}$ & $4.1 \mathrm{~Hz}$ & $9.3 \mathrm{~Hz}$ & $14.0 \mathrm{~Hz}$ & $4.1 \mathrm{~Hz}$ & $9.3 \mathrm{~Hz}$ & $14.0 \mathrm{~Hz}$ & $\begin{array}{l}4.1 \\
\mathrm{~Hz}\end{array}$ & $9.3 \mathrm{~Hz}$ & $\begin{array}{r}14.0 \\
\mathrm{~Hz}\end{array}$ \\
\hline $60 \mathrm{~mm}$ & 4,3 aa & $6.0 \mathrm{aa}$ & $14.2 \mathrm{ab}$ & 45 aa & $125 \mathrm{ab}$ & $146 \mathrm{ab}$ & $1.8 \mathrm{aa}$ & $4.0 \mathrm{ab}$ & $4.5 \mathrm{ab}$ & 2.4 & 1.5 & 3.2 \\
\hline $100 \mathrm{~mm}$ & 9,6 ba & $16.6 \mathrm{ba}$ & $9.0 \mathrm{aa}$ & $102 \mathrm{ba}$ & 104 aa & 119 aa & $3.2 \mathrm{aa}$ & $5.7 \mathrm{ab}$ & $7.9 \mathrm{bc}$ & 3.0 & 2.9 & 1.1 \\
\hline $180 \mathrm{~mm}$ & $9,6 \mathrm{~b}-$ & - & - & $139 \mathrm{~b}-$ & - & - & $4.9 \mathrm{~b}-$ & - & - & 2.0 & - & 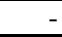 \\
\hline
\end{tabular}

Figures followed by different letters show significant differences in a LSD test at $95 \%$ significance. The first letter compares columns (strokes) and the second letter compares rows (frequencies).

It can be observed that tangential forces were, on average, 1.1 to 3.2 times lower than translational forces.

In the case of $4.1 \mathrm{~Hz}$, when the stroke increased, the linear force increased from $4.3 \mathrm{~N}$ to $9.6 \mathrm{~N}$ when passing from $60 \mathrm{~mm}$ to $100 \mathrm{~mm}$, but there were no differences between strokes of $100 \mathrm{~mm}$ and $180 \mathrm{~mm}$. The angle $\alpha$ also increased, the difference between the $60 \mathrm{~mm}\left(45^{\circ}\right)$ and $100 \mathrm{~mm}\left(102^{\circ}\right)$ strokes being higher than that between this and $180 \mathrm{~mm}\left(139^{\circ}\right)$. The tangential force experienced an almost linear increase with the stroke. In the case of $9.3 \mathrm{~Hz}$, there was a clear increment in the linear force when the stroke increased, but the differences were not important for angle $\alpha$ and the tangential force. In the case of $14.0 \mathrm{~Hz}$, there were no significant differences for $F$ and $\alpha$, but there was a clear increase for $F t$.

If the effect of the frequency is analysed in relation to the stroke, $F$ increases exponentially with frequency in the case of the stroke of $60 \mathrm{~mm}$, in accordance with:

$$
F=2.27+0.058269 f^{2}\left(\mathrm{R}^{2}=67 \%\right)
$$

On the other hand, $\alpha$ increased rapidly when passing from $4.1 \mathrm{~Hz}$ to $9.3 \mathrm{~Hz}$, but slowly when rising from $9.3 \mathrm{~Hz}$ to $14.0 \mathrm{~Hz}$. The equation that was found to adjust the data best was:

$$
\alpha=188.302-588.771 / f\left(\mathrm{R}^{2}=54 \%\right)
$$

In the case of $F t$, a pattern similar to $\alpha$ was found. For the stroke of $100 \mathrm{~mm}$, there were no significant differences between $F$ and $\alpha$ in terms of frequency, but there was an almost linear increase in $F t$ with the frequency.

In general, it was observed that the lowest frequency combined with the lower stroke produced linear forces, tangential forces and bending angles that were clearly lower than the combinations that involved higher strokes and frequencies, between which there were no clear differences. 


\section{Conclusions}

The analysis of the vibration behaviour of fruit during mechanical harvesting using shakers can be performed using slow-motion cameras and image processing techniques. Such an approach overcomes the shortcomings of systems using physical sensors, which can introduce uncertainty in the results, or manual analyses of video sequences, which are tedious, subjective and highly time-consuming. In this work, the movement of different cultivars of citrus fruits was filmed and the principal parameters analysed. An important problem to be solved arose from the low resolution of the images, which greatly influences the signals obtained, since a few pixels of error in the estimation of the theoretically same position between subsequent images is interpreted as big jumps in the speed or acceleration signals. This source of error has been minimised by filtering the signals using a Gaussian filter.

The technique applied has allowed the dynamic forces experienced by the fruit to be measured and it was observed that:

- The tangential forces were, on average, lower than the translational forces.

- There were significant interactions for the force applied between the strokes and frequencies tested.

- In the case of the lower frequency tested, when the stroke increased from 60 to $100 \mathrm{~mm}$ the linear force and the angle $\alpha$ increased positively, but no differences were found between 100 and $180 \mathrm{~mm}$.

- In the test performed using a frequency of $9.3 \mathrm{~Hz}$, when the stroke increased, so did the linear force, but the differences were not significant for angle $\alpha$ and tangential force Ft. In the case of 14.0 Hz, in contrast, there were no significant differences for $F$ and $\alpha$, but there was a clear increase for $F t$.

Both the methodology presented here and the software that was developed can be used to study and gain a better understanding of fruit detachment phenomena.

\section{Acknowledgements}

This work was founded by the Instituto Nacional de Investigación y Tecnología Agraria y Alimentaria (INIA) through the projects RTA2009-00118-C02-01 and RTA2009-00118-C02-02, and co-founded by European FEDER founds.

\section{References}

Adrian, P.A., \& Fridley, R.B. (1958). Mechanical fruit tree shaking. California Agriculture 12:10, October.

Alper, Y., \& Foux, A. (1976). Strength Properties of Orange Fruit Stem Joints. Transactions of the ASAE 412-416.

Blasco, J., Cubero, S., Gómez-Sanchis, J., Mira, P. \& Moltó, E. (2009). Development of a machine for the automatic sorting of pomegranate (Punica granatum) arils based on computer vision. Journal of Food Engineering, 90, 27-34.

Chou, P., \& Brown, C. (1990). The Theory and Practice of Bayesian Image Labeling. International Journal of Computer Vision, 4, 185-210.

Cubero, S., Aleixos, N., Albert, A., Torregrosa, A., Ortiz, C., García-Navarrete, O., \& Blasco, J. (2013). Optimised computer vision system for automatic pre-grading of citrus fruit in the field using a mobile platform. Precision Agriculture (In press). DOI: 10.1007/s11119-013-9324-7.

Cubero, S., Aleixos, N., Moltó, E., Gómez-Sanchis, J., \& Blasco, J. (2011). Advances in machine vision applications for automatic inspection and quality evaluation of fruits and vegetables. Food and Bioprocess Technology 4(4), 487-504.

Diener, R.G., Levin, J.H. \& Whittengerger, R.T. (1968). Frequency and stroke studies for shaking apples. ASAE paper No 68-662, ASAE, St. Joseph, MI. 49085. 
Edan, Y., Rogozin, D., Flash, T., \& Miles, G. E. (2000). Robotic melon harvesting. IEEE Transactions on Robotics and Automation, 16 (6), 831-834.

FAO. (2012). Citrus world production 2010.

http://faostat.fao.org/site/567/DesktopDefault.aspx?PageID=567\#ancor. Accessed October 2013.

Freeman, H. (1961). On the encoding of arbitrary geometric configurations. IRE Transactions of Electronic Computers. EC-10, 260-268.

Garman, C.F., Diener, R.G. \& Stafford, J.R. (1972). Effect of shaker type and direction of shake on apple detachment. Journal Ag. Eng. Res. 17, 195-205.

Guo, F., Cao Q., \& Nagata, M. (2008). Fruit detachment and classification method for strawberry harvesting Robot. International Journal of Advanced Robotic Systems 5(1): 41-48.

Intercitrus. (2012). Aforo Citricos 2010/2011 http://www.intercitrus.org/intercitrus/. Accessed July 2012.

Jimenez, A.R., Ceres, R., \& Pons, J.L. (2000). A Survey of Computer Vision Methods for Locating Fruit on Trees. Transactions of the ASAE, Vol.43, No.6, pp. 1911-1920

Kondo, N., Ninomiya, K., Hayashi, S., Ota, T., \& Kubota K. (2005). A New Challenge of Robot for Harvesting Strawberry Grown on Table Top Culture, Proceedings of ASAE Annual International Meeting Tampa, Paper Number: 053138 [CDROM], ISBN 0- 929355-94-6, Florida, USA. July 2005, ASAE Publisher, St Joseph, MI

Lenker, D. H. \& Hedden, S.L. (1968). Optimum shaking action for citrus fruit harvesting. Transactions of the ASAE 11 (3): 347-349.

Ling, P.P, Ehsani, R., Ting, K.C., Chi, Y., Ramalingam N., Klingman M.H., \& Draper, C. (2004). Sensing and End-Effector for a Robotic Tomato Harvester, Proceedings of ASAE/CSAE Annual International Meeting Ottawa, Paper Number: 043088 [CDROM], ISBN 0-929355-94-6, Ontario, Canada. August 2004, ASAE Publisher, St Joseph, MI

López, F.J., \& Gracia, C. (1979). Modelización del subsistema pedúnculo-fruto de olivo. Ed. An. INIA/Ser. Tecnol.agr./N.5. Separata no 6 (pág. 119-153).

Lorente, D., Aleixos, N., Gómez-Sanchis, J., Cubero, S., García-Navarrete, O.L., \& Blasco, J. (2012). Recent advances and applications of hyperspectral imaging for fruit and vegetable quality assessment. Food and Bioprocess Technology 5(4), 1121-1142.

Mizushima, A. \& Lu, R. (2010). Cost benefits analysis of in-field presorting for the apple industry. Applied Engineering in Agriculture 27(1): 22-40.

Muscato, G., Prestifilippo, M., Abbate, N., \& Rizzuto, I. (2005). A prototype of an orange picking robot: past history and experimental results. Industrial Robot, 32(2), 128-138.

Navarro, L., Pina, J.A., Juarez, J., Ballester-Olmos, J.F., Arregui, J.M., Ortega, C., Navarro, A., DuranVila, N., Guerri, J., Moreno, P., Cambra, M., \& Zaragoza, S. (2002). The citrus variety improvement program in Spain in the period 1975-2001. In: Proceedings of the 15th Conference of the International Organization of Citrus Virologists. IOCV, Riverside, pp. 306-316.

Ortiz, C., \& Torregrosa, A. (2013). Determining Adequate Vibration Frequency, Amplitude and Time for Mechanical Harvesting of Fresh Mandarins. Transactions of the ASABE, 56(1):15-22

Parchomchuk, P., \& Cooke, R. (1972). Vibratory harvesting: an experimental analysis of fruit-stem dynamics. Transactions of the ASAE 598-603.

Qiao, J., Sasao, A., Shibusawa, S., Kondo, N., \& Morimoto E. (2005). Mapping Yield and Quality using the Mobile Fruit Grading Robot. Biosystems Engineering, Vol.90, No.2, pp. 135-142,

Rumsey, J., \& Barnes, K. K. (1970). Detachment Characteristics of Desert-Grown Oranges and Grapefruit. Transactions of the ASAE. 528-530.

Sanders, K. F. (2005). Orange Harvesting Systems Review. Biosystems Engineering 90 (2), 115-125.

Torregrosa, A., Ortí, E., Martín, B., Gil, J., Ortiz, C. (2009). Mechanical harvesting of oranges and mandarins in Spain. Biosystems Engineering 104 (2009) 18-24.

Tsatsarelis, C.A. (1987). Vibratory olive harvesting: The response of fruit-stem system to fruit removing actions. J. Agric. Eng. Res. (38):77-90. 
Van Henten, E., Hemming, J., Van Tuijl, B., Kornet, J., Meuleman, J., Bontsema, J., \& Van Os, E. (2002). An autonomous robot for harvesting cucumbers in greenhouses. Autonomous Robots, 13(2), 241258.

Vidal, A., Talens, P., Prats-Montalbán, J.M., Cubero,S., Albert, F., Blasco, J. (2012). In line estimation of the standard colour index of citrus fruits using a computer vision system developed for a mobile platform. Food and Bioprocess Technology. DOI: 10.1007/s11947-012-1015-2 (In press).

Young, H. D., \& Freedman, R.A. (2006). University Physics. Addison-Wesley. 708 pp.

Zhang, Q. (2012). Fruit removal efficiency of a mechanical shaker for sweet Cherry Harvest. International Symposium on Mechanical Harvesting \& Handling Systems of Fruits and Nuts. April 1-4, 2012. Lake Alfred, FL, USA. 


\begin{tabular}{|c|c|}
\hline Figure & Caption \\
\hline Figure 1 & Vision and shaker system \\
\hline Figure 2 & $\begin{array}{l}\text { Left: Initial position of the fruit, where the projected equatorial diameter of the quasi- } \\
\text { spherical object matches the real one. Right: Position of the fruit, where the projected } \\
\text { equatorial diameter (in green) does not match the real one (in yellow indicated by the two } \\
\text { labels) }\end{array}$ \\
\hline Figure 3 & $\begin{array}{l}\text { Left: Movements experienced by the fruit (yellow arrow for spinning motion, blue arrow for } \\
\text { pendulum motion and green arrows for displacements of the fruit centroid); main axes of the } \\
\text { fruit and peduncle are also depicted. Centre and right: 'Equatorial diameter fruit/stem' angle } \\
\text { and 'Equatorial diameter fruit/horizontal axis' angle in two different sequences }\end{array}$ \\
\hline Figure 4 & $\begin{array}{l}\text { a) trajectory followed by the centroid of the fruit; b) evolution of the } X \text { coordinate of the } \\
\text { centroid through the different frames; c) evolution of the estimated speed; d) evolution of the } \\
\text { estimated acceleration (for all the images, the red signal shows the original values and the } \\
\text { blue signals the data after filtering) }\end{array}$ \\
\hline Figure 5 & Evolution of the filtered angle between the stem and polar axis of the fruit \\
\hline Figure 6 & $\begin{array}{l}\text { Flowchart of the processes of image analysis and subsequent calculation of dynamic } \\
\text { parameters }\end{array}$ \\
\hline Figure 7 & 'Navel Lane Late' orange during the quasi-static traction test at a traction angle of $0^{\circ}$ \\
\hline
\end{tabular}


Figure
Click here to download high resolution image
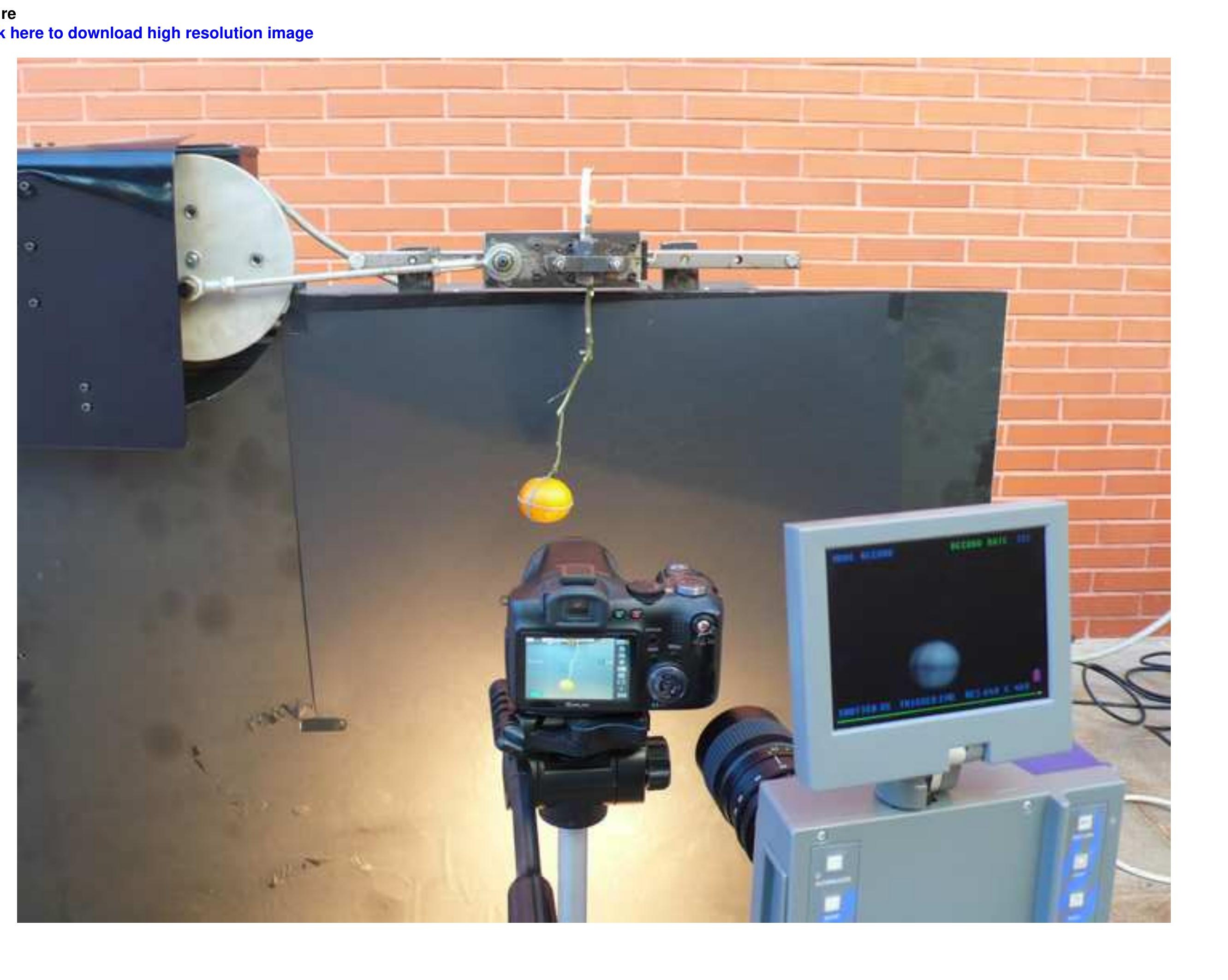

(1)
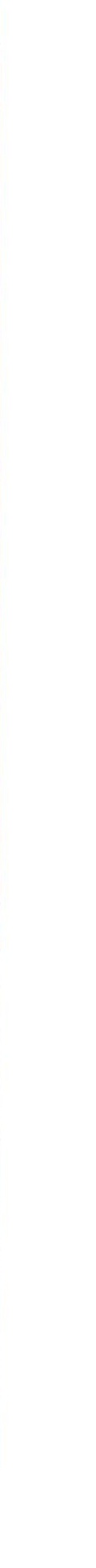

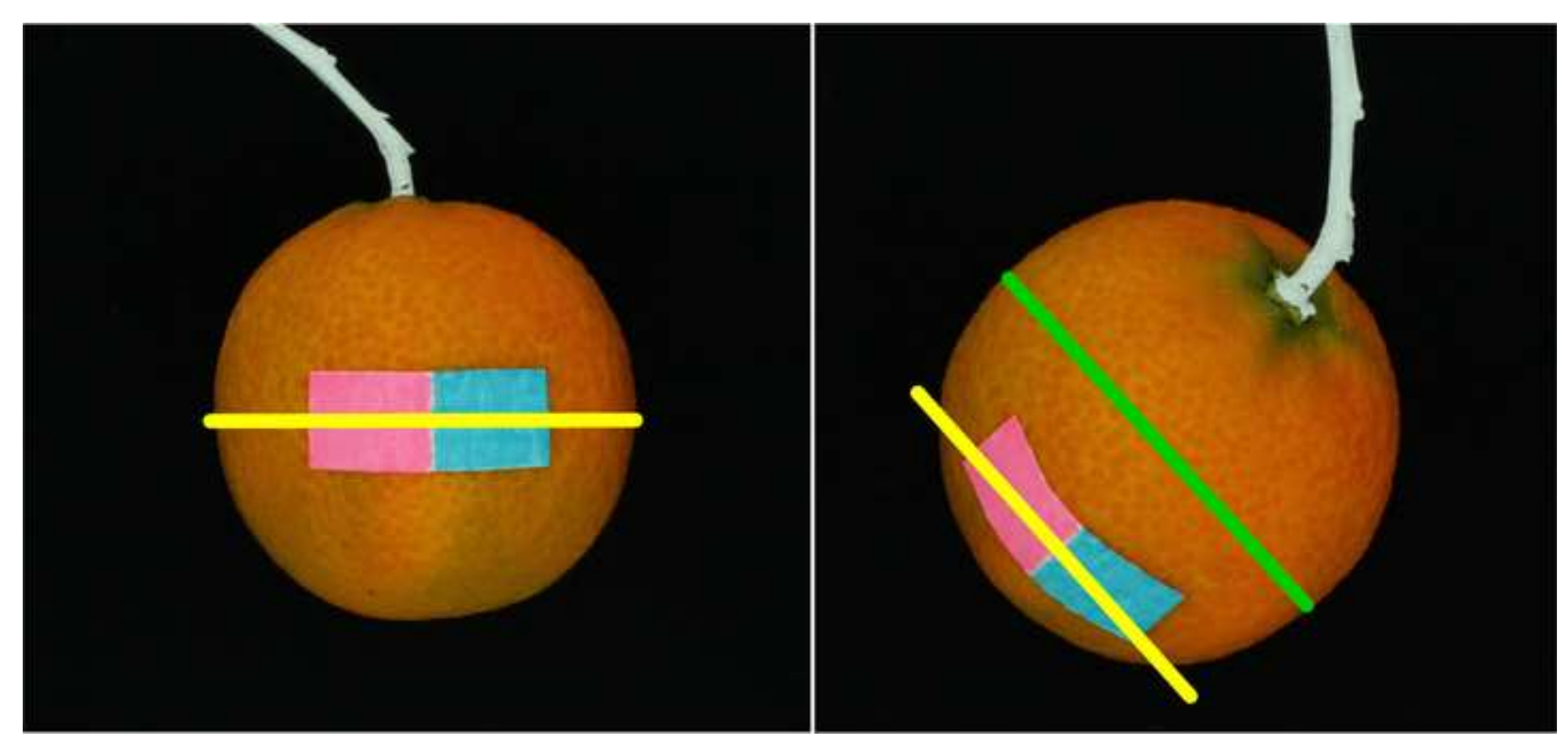

Click here to download high resolution image 


\section{Figure}

Click here to download high resolution image

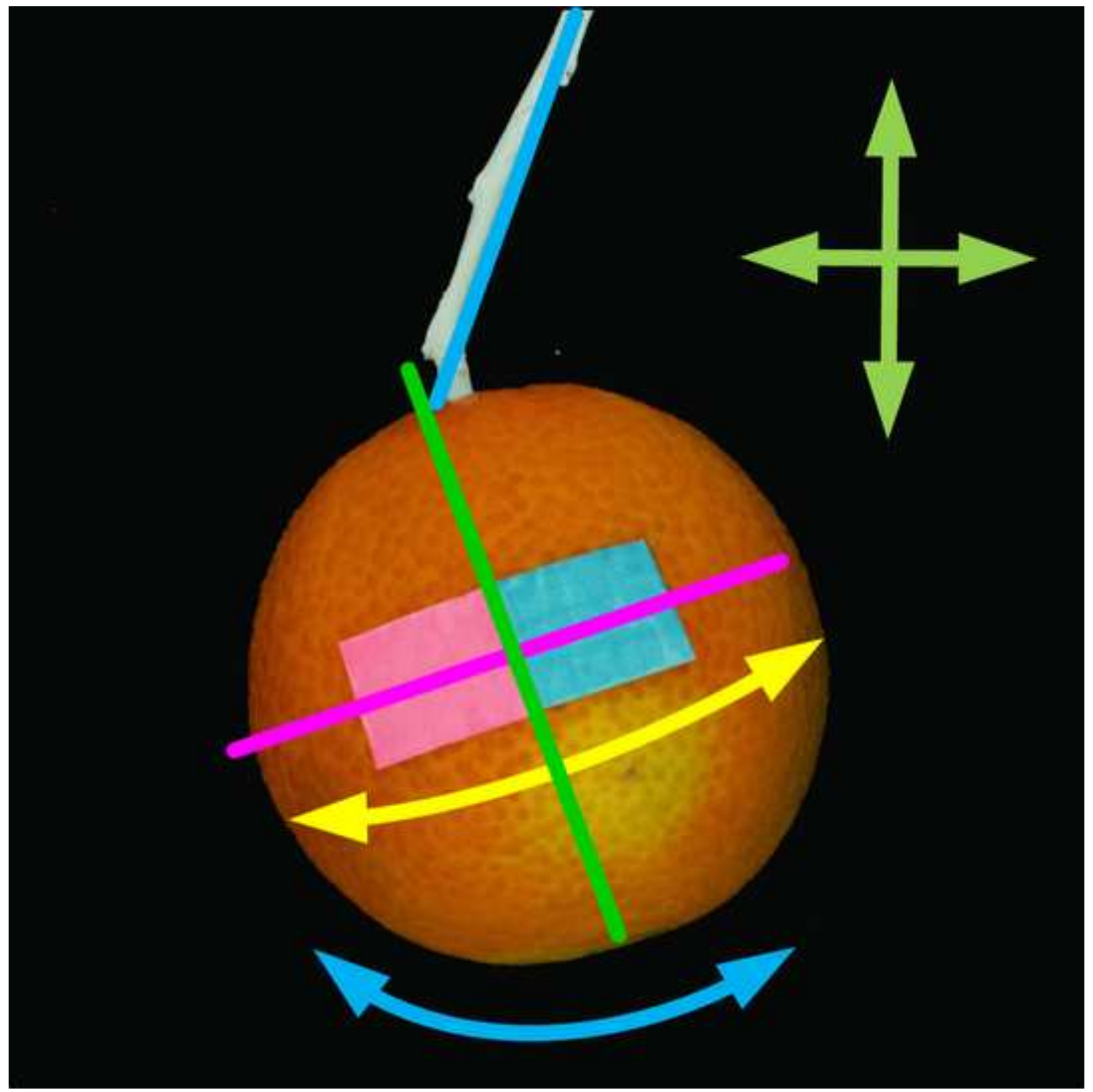




\section{Figure}

Click here to download high resolution image

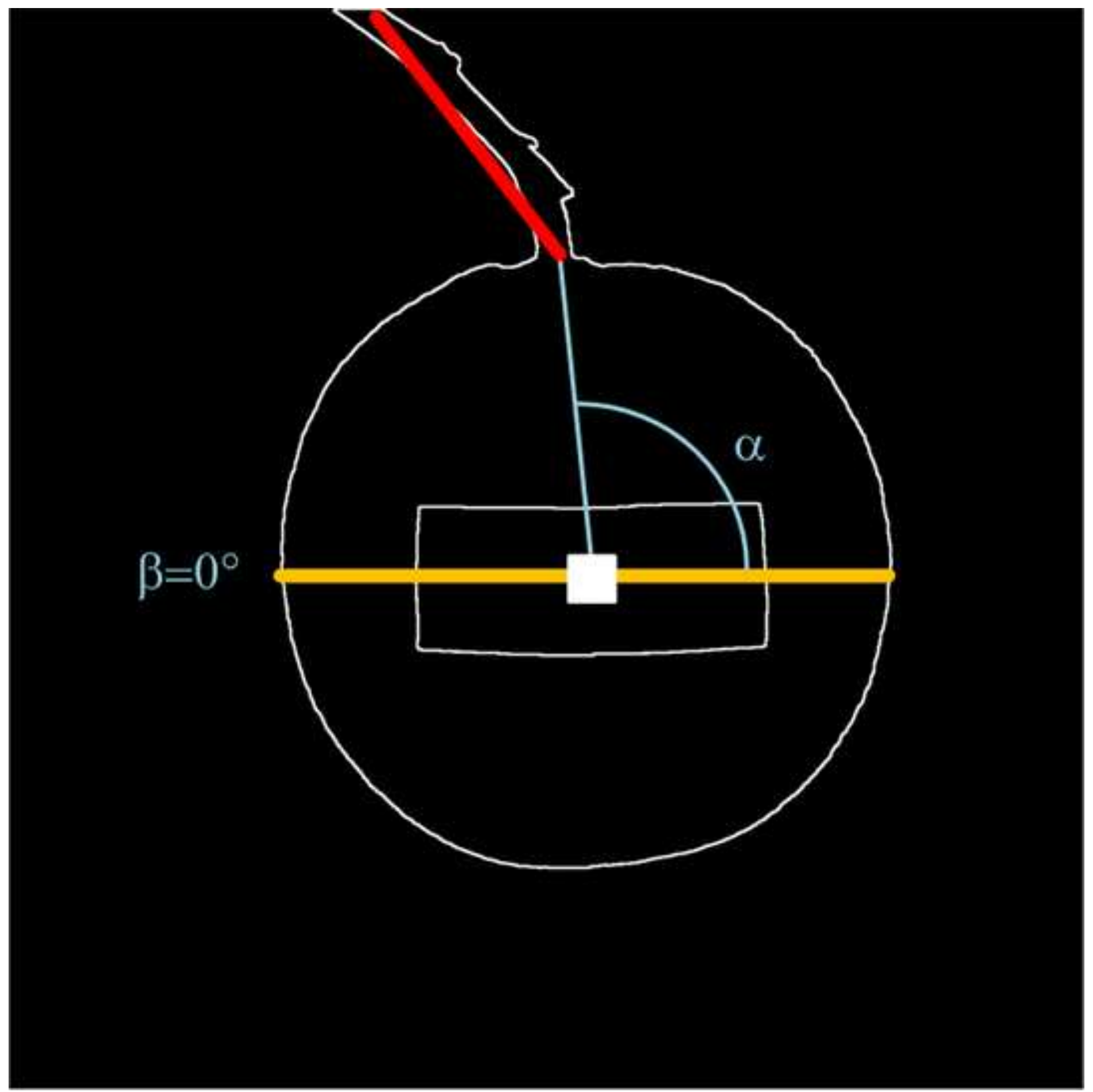




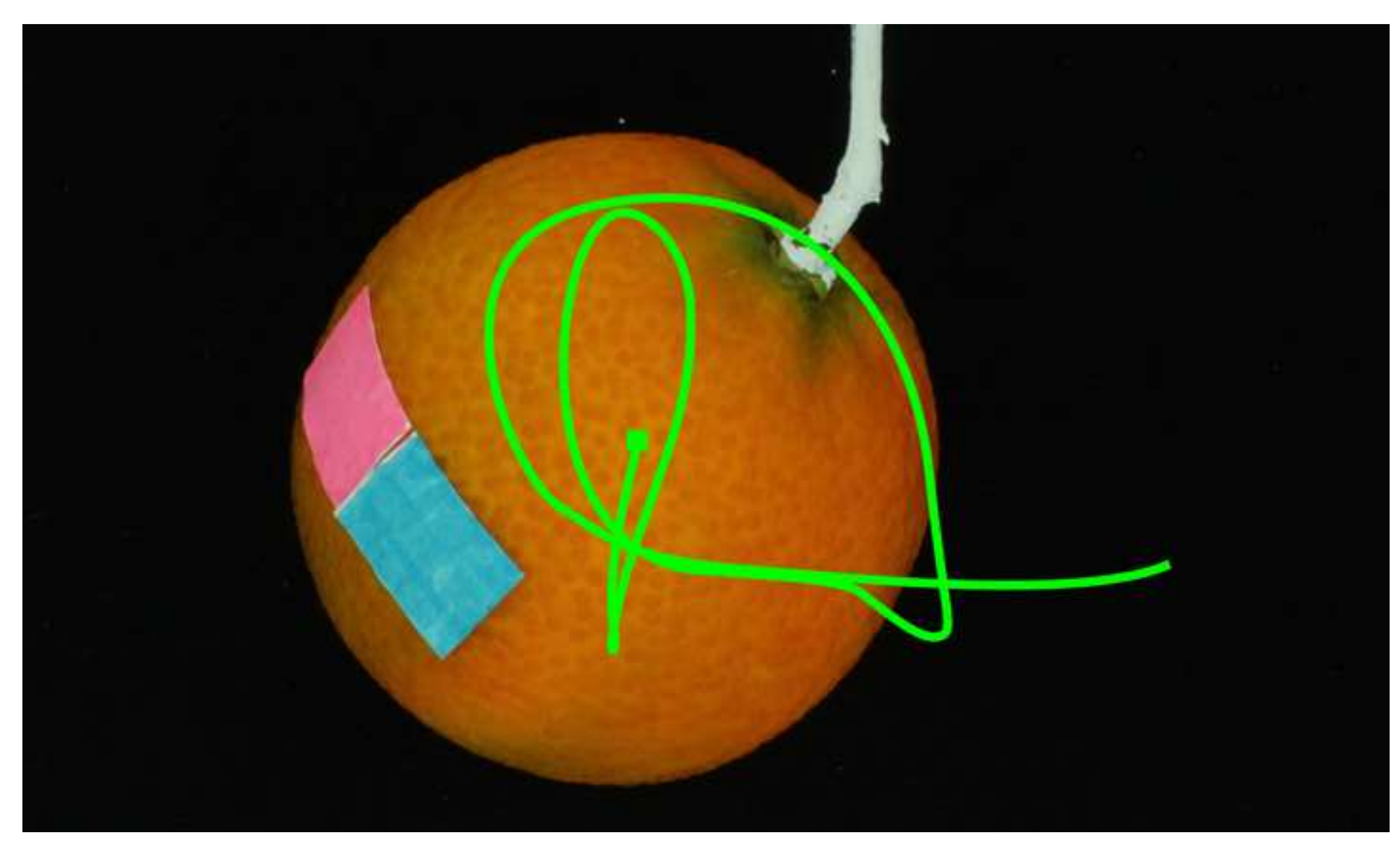

Click here to download high resolution image 


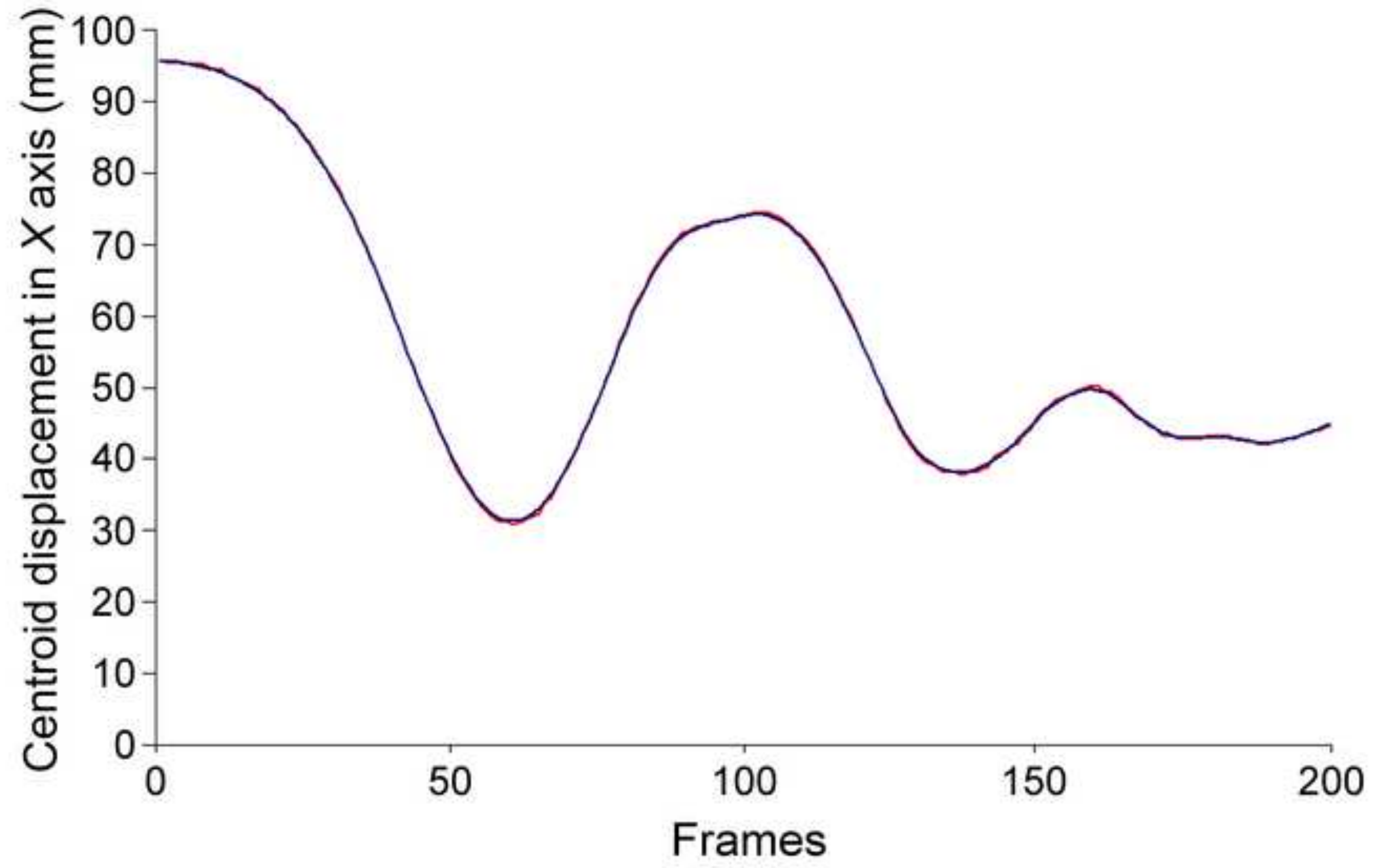




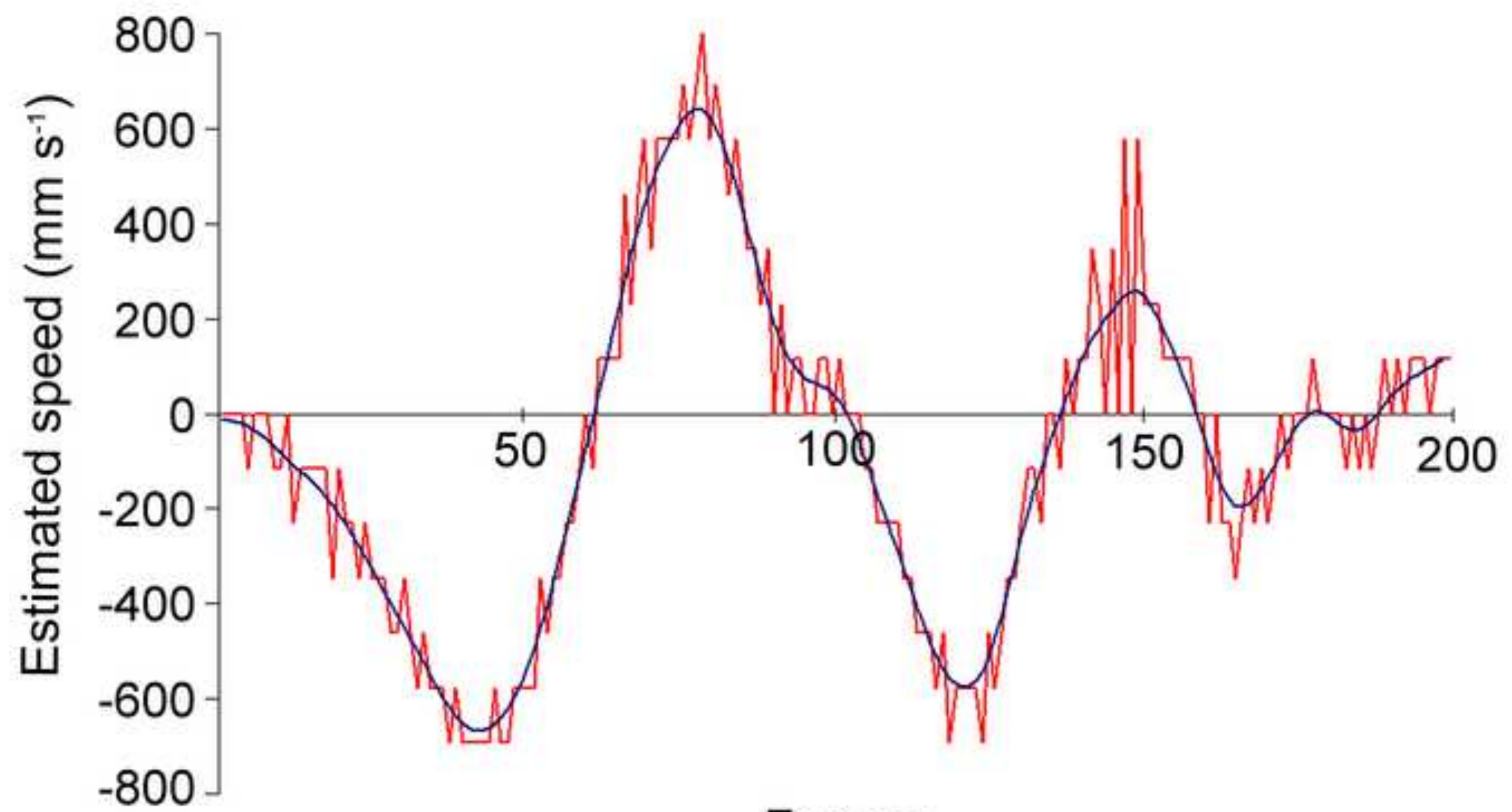

Frames 


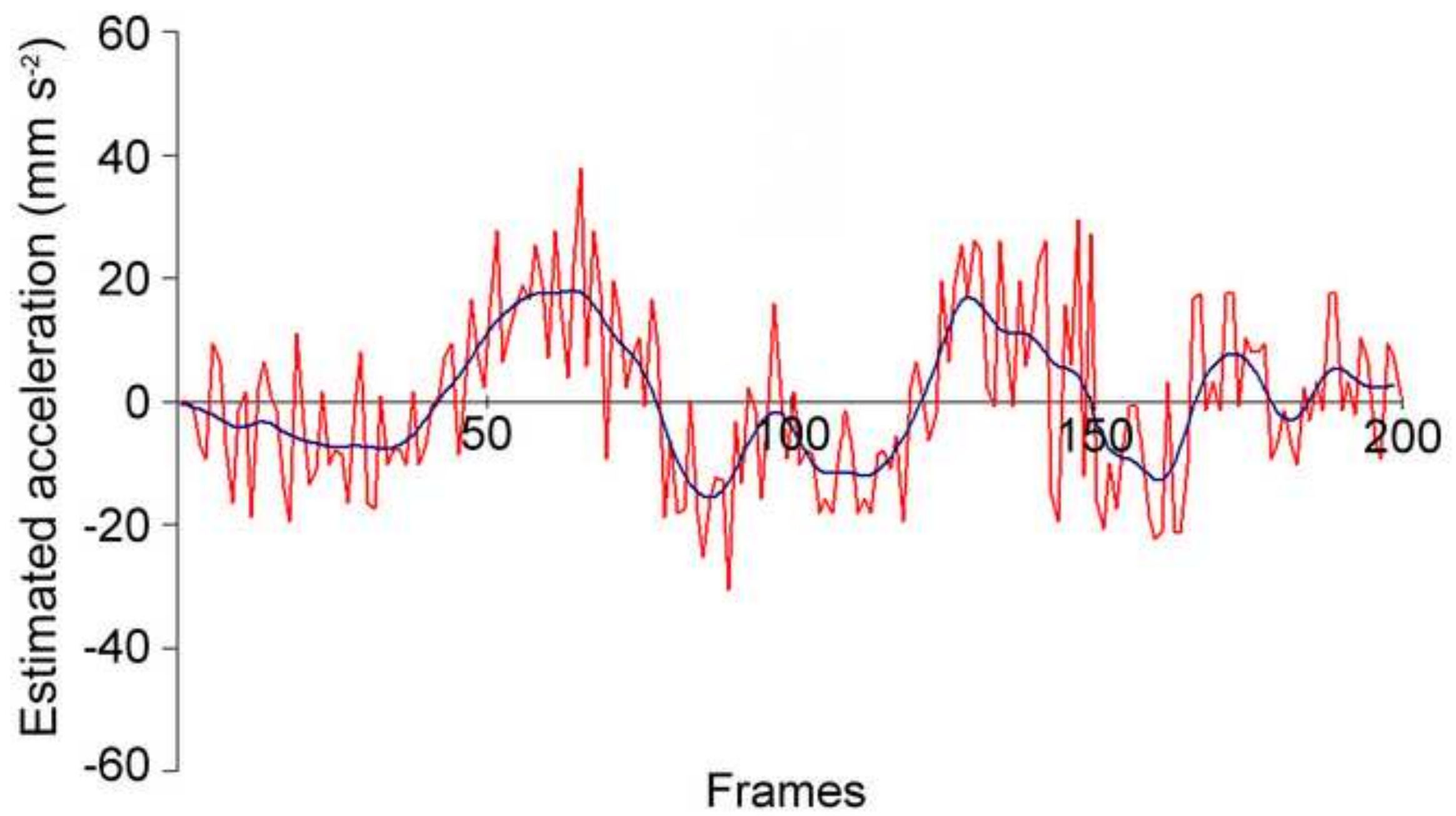




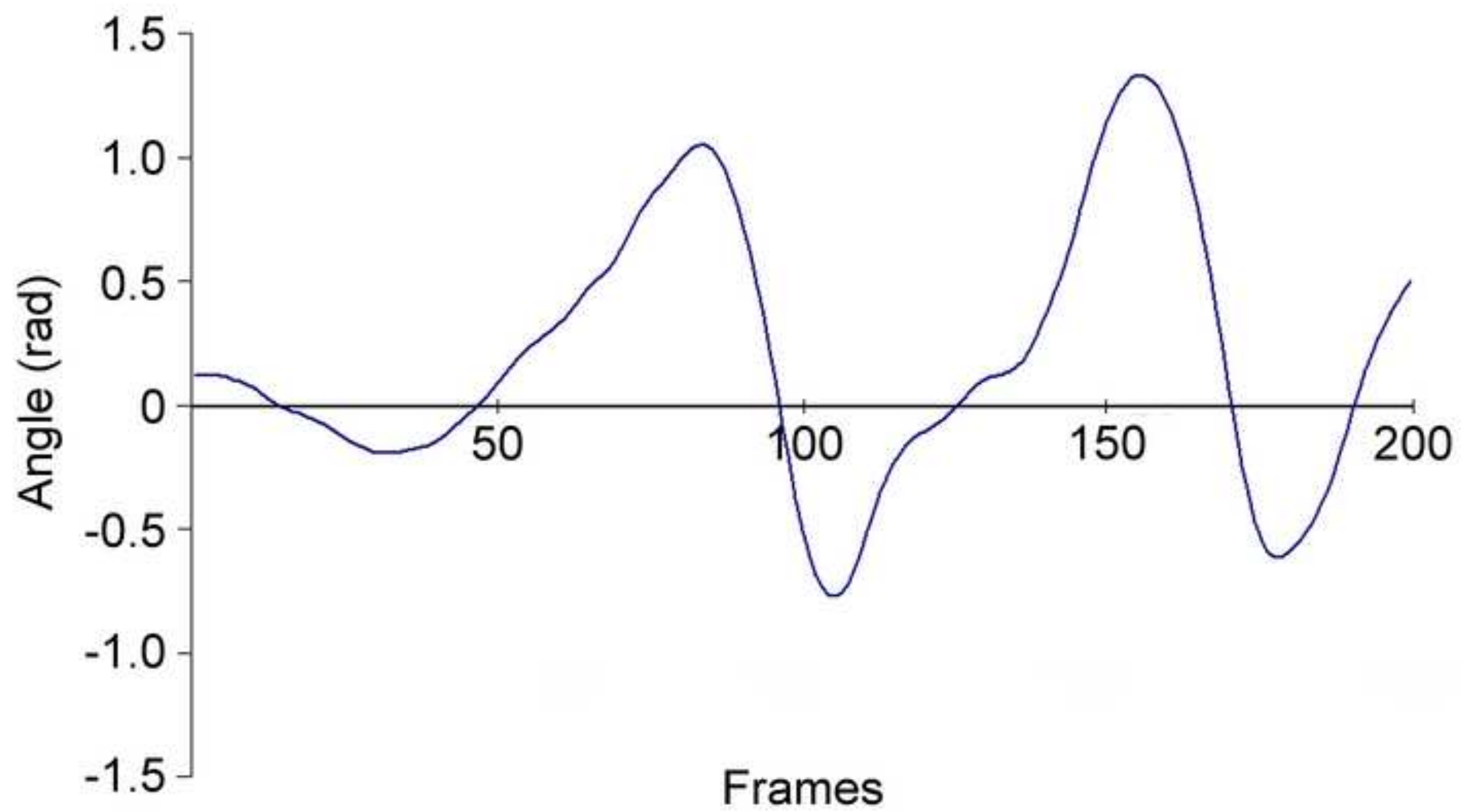




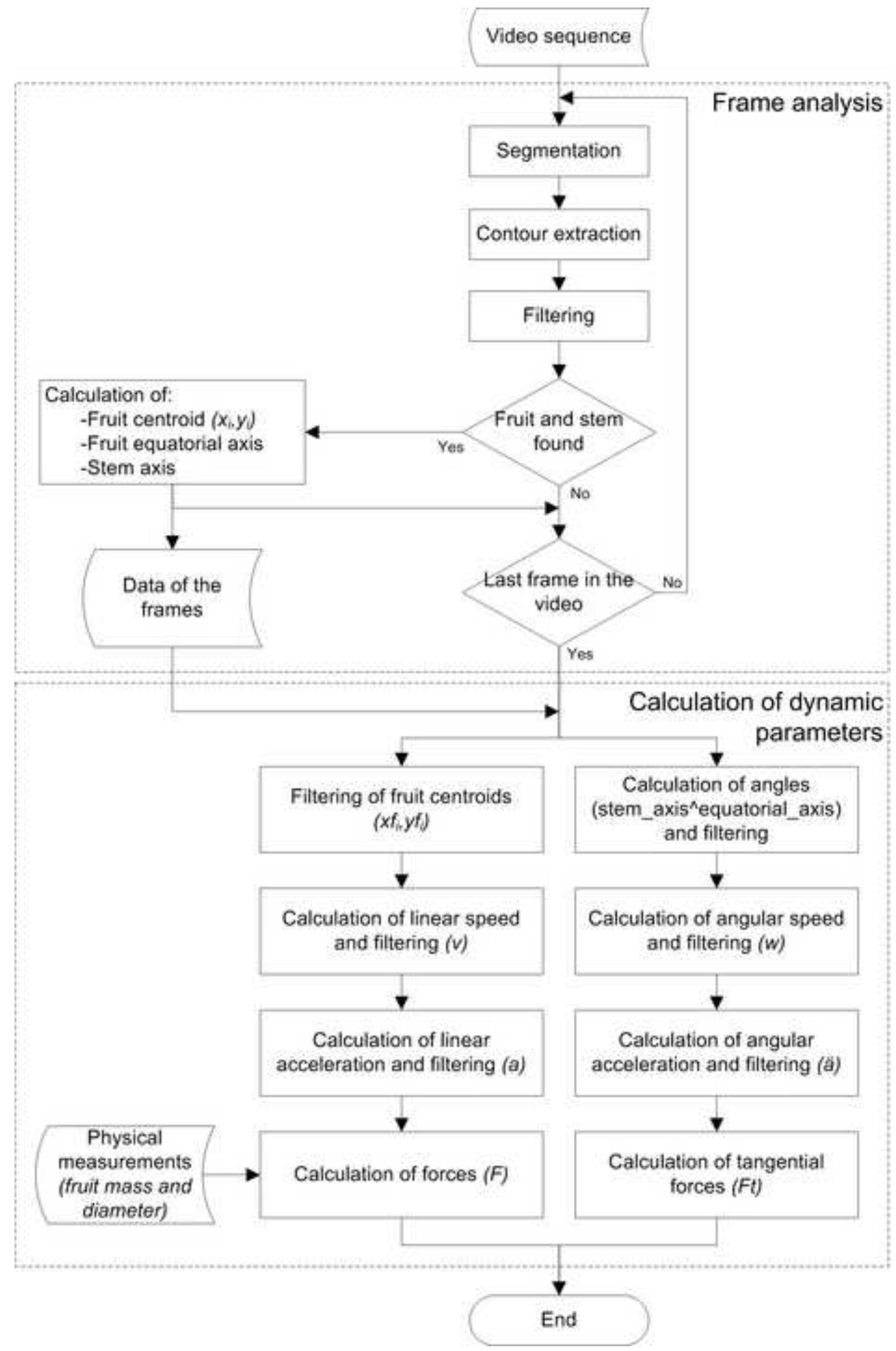


Flick here to download high resolution image

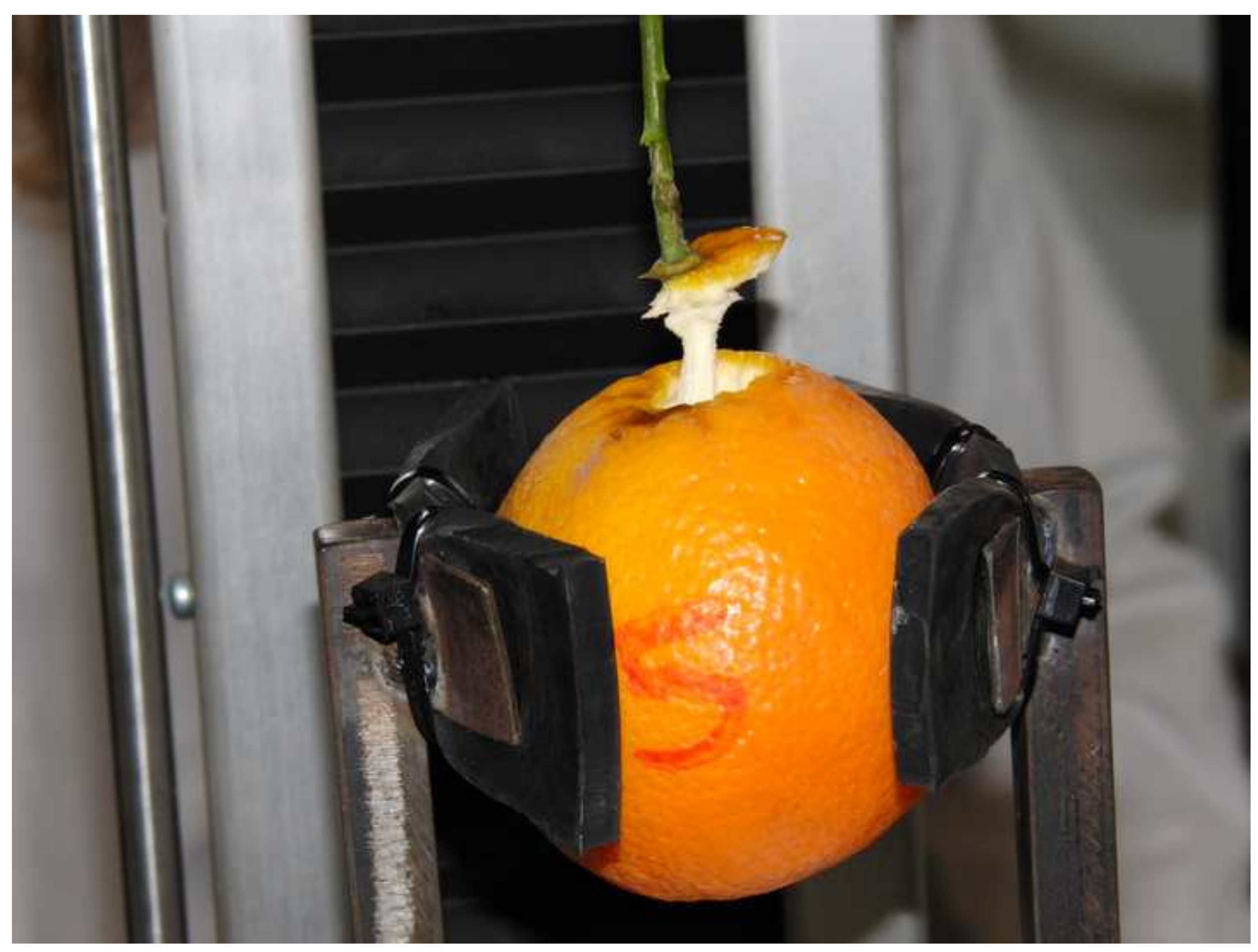




\section{TABLES}

Table 1. Average traction force needed to detach the fruits in quasi-static tests at different angles

Table 2: Theoretical and estimated accelerations from the laboratory shaker videos

Table 3. Acceleration, forces and ratios between a theoretical sinus wave, drill chuck and fruit center of oranges 'Valencia'.

Table 4: Inertial forces obtained from the shaken fruits (NA: not analysed).

Table 5. Translational forces $(F)$, tangential forces $(F t)$ and fruit-peduncle bending angle $(\alpha)$ measured in the fruits according to the stroke and frequency applied to mandarins 'Nova' 
Table 1. Parameters measured in the fruit (average values and standard deviation between brackets)

\begin{tabular}{|c|c|c|c|c|c|c|c|c|}
\hline Variety & $\begin{array}{c}\text { Fruit } \\
\text { mass } \\
(\mathrm{g})\end{array}$ & $\begin{array}{l}\text { Equatorial } \\
\text { diameter } \\
(\mathrm{mm})\end{array}$ & $\begin{array}{c}\text { Polar } \\
\text { diameter } \\
(\mathbf{m m})\end{array}$ & $\begin{array}{l}\text { Peduncle } \\
\text { diameter } \\
(\mathrm{mm})\end{array}$ & ${ }^{\mathbf{o}}$ Brix & $\begin{array}{c}\text { Maturity } \\
\text { Index }^{\mathrm{a}}\end{array}$ & $\begin{array}{l}\text { Traction } \\
\text { Force } \\
\text { (N) }\end{array}$ & $\begin{array}{c}\text { Harvesting } \\
\text { date }\end{array}$ \\
\hline Eureka $^{1}$ & $218(87)$ & 70.7 (10) & 92 (13) & $2.9(0.3)$ & 6.6 & 1.24 & $118(40)$ & $\begin{array}{r}\text { 23rd March } \\
2011\end{array}$ \\
\hline $\begin{array}{l}\text { Navel } \\
\text { Lane } \\
\text { Late }^{1}\end{array}$ & $280(66)$ & $81(6)$ & 77 (7) & $3.5(0.4)$ & 11.8 & 8.47 & $71(6.0)$ & $\begin{array}{r}\text { 31st March } \\
2011\end{array}$ \\
\hline Valencia $^{1}$ & $181(31)$ & $72(5)$ & $68(5)$ & $3.0(0.2)$ & 11.8 & 4.8 & $45(23)$ & $\begin{array}{r}25 \text { th March } \\
2011\end{array}$ \\
\hline Marisol $^{2}$ & $95(25)$ & $58(4)$ & $52(5)$ & $4.2(0.8)$ & 9.8 & 5.5 & $39(9.2)$ & $\begin{array}{r}5 \text { th Oct } \\
2011\end{array}$ \\
\hline Nova $^{2}$ & $103(25)$ & $62(7)$ & $50(4)$ & $3.2(0.5)$ & 12.2 & 9.2 & $63(9.8)$ & $\begin{array}{r}\text { 24th Nov } \\
2011\end{array}$ \\
\hline Valencia $^{2}$ & $151(36)$ & $63(7)$ & $69(4)$ & $2.7(0.2)$ & 9.3 & 7.5 & $58(12.3)$ & $\begin{array}{r}\text { 9th May } \\
2011\end{array}$ \\
\hline
\end{tabular}


Table 2. Traction force needed to detach the fruits at three different angles in the quasi-static tests

\begin{tabular}{|c|c|c|c|c|}
\hline & Level & \multicolumn{2}{|c|}{$F d(\mathbf{N})$} & $F d / F_{0}$ \\
\hline & & average $^{1}$ & sd & \\
\hline \multirow{3}{*}{ Angle (degrees) } & $0^{0}$ & $92^{\mathrm{a}}$ & 32 & 1.00 \\
\hline & $45^{0}$ & $61^{b}$ & 21 & 0.66 \\
\hline & $90^{\circ}$ & $38^{c}$ & 15 & 0.41 \\
\hline \multirow{3}{*}{ Variety } & 'Eureka' lemon & $76^{a}$ & 45 & \\
\hline & 'Navel Lane Late' orange & $68^{a}$ & 28 & \\
\hline & 'Valencia' orange & $49^{b}$ & 23 & \\
\hline \multirow{9}{*}{ Angle $x$ Variety } & $0^{0} \times$ Eureka & 120 & 41 & 1 \\
\hline & $0^{0}$ x Navel Lane Late & 93 & 26 & 1 \\
\hline & $0^{0} \mathrm{x}$ Valencia & 72 & 17 & 1 \\
\hline & $45^{0} \times$ Eureka & 73 & 25 & 0.60 \\
\hline & $45^{0} \times$ Navel Lane Late & 65 & 20 & 0.70 \\
\hline & $45^{0} \times$ Valencia & 47 & 13 & 0.65 \\
\hline & $90^{\circ} \mathrm{x}$ Eureka & 36 & 13 & 0.30 \\
\hline & $90^{\circ} \times$ Navel Lane Late & 46 & 14 & 0.49 \\
\hline & $90^{\circ} \times$ Valencia & 27 & 10 & 0.37 \\
\hline \multicolumn{5}{|c|}{$F d$, traction force; $F_{o}$, traction force at angle $0^{0} ;$ sd, standard deviation } \\
\hline & lenote statistically signific & sc & 1 & \\
\hline
\end{tabular}


Table 3. Theoretical and estimated accelerations obtained from the analysis of the videos

\begin{tabular}{|c|c|c|c|}
\hline Stroke $(2 X), \mathrm{mm}$ & Frequency $f, \mathrm{~Hz}$ & $\begin{array}{c}\text { Theoretical acceleration } \\
\text { SHM } \operatorname{Abs}\left(a_{\max }\right), \mathrm{m} \mathrm{s}^{-2}\end{array}$ & $\begin{array}{c}\text { Real acceleration } \\
\operatorname{Abs}\left(a_{\max }\right), \mathrm{m} \mathrm{s}^{-2}\end{array}$ \\
\hline 63 & 9.4 & 109 & 107 \\
\hline 100 & 8.8 & 152 & 163 \\
\hline 79 & 17.4 & 471 & 488 \\
\hline
\end{tabular}


Table 4. Comparison of accelerations and forces between a theoretical sinus wave and the fruit centre of 'Valencia' oranges

\begin{tabular}{|c|c|c|c|c|c|c|c|c|c|c|c|}
\hline \multirow{2}{*}{$\begin{array}{c}\text { Stroke } \\
\mathbf{m}\end{array}$} & \multirow{2}{*}{$\begin{array}{c}\text { Freq } \\
\mathbf{H z}\end{array}$} & \multicolumn{3}{|c|}{ Acceleration, $\mathrm{m} \mathrm{s}^{2}$} & \multicolumn{2}{|c|}{ Linear forces, $\mathbf{N}$} & \multirow{2}{*}{$\begin{array}{c}\text { Tan. } \\
\text { force, } \\
\text { N }\end{array}$} & \multicolumn{2}{|c|}{$\begin{array}{l}\text { Fruit traction } \\
\quad \text { force, } \mathbf{N}\end{array}$} & \multicolumn{2}{|c|}{ Detachment } \\
\hline & & $\begin{array}{l}\text { Theo- } \\
\text { retical }\end{array}$ & $\begin{array}{c}\text { Ob- } \\
\text { served }\end{array}$ & Ratio & $\begin{array}{l}\text { Theo- } \\
\text { retical }\end{array}$ & $\begin{array}{c}\text { Ob- } \\
\text { served }\end{array}$ & & $\mathbf{0}^{\circ}$ & $90^{\circ}$ & time, $s$ & $\begin{array}{l}\text { cycles, } \\
\text { num. }\end{array}$ \\
\hline 0.100 & 8.8 & 152 & 108 & 0.71 & 24 & 17 & 10 & 58 & 19 & 0.503 & 4.4 \\
\hline 0.063 & 9.4 & 109 & 78 & 0.72 & 14 & 10 & 8 & 58 & 19 & 1.655 & 15.5 \\
\hline 0.079 & 17.4 & 471 & 68 & 0.14 & 75 & 11 & 9 & 58 & 19 & 0.495 & 8.6 \\
\hline
\end{tabular}


Table 5. Inertial forces estimated from the videos of the shaken fruits

\begin{tabular}{|c|c|c|c|c|c|c|c|c|c|}
\hline Variety & $\begin{array}{c}\text { stroke } \\
(\mathbf{m m})\end{array}$ & $\begin{array}{c}\mathbf{f} \\
(\mathbf{H z})\end{array}$ & $\begin{array}{c}\text { Linear } \\
\mathbf{f o r c e} \\
(\mathbf{N})\end{array}$ & $\begin{array}{c}\text { Fruit } \\
\text { rotation } \\
\left(\boldsymbol{\beta} \boldsymbol{,}^{\circ}\right)\end{array}$ & $\begin{array}{c}\text { Fruit-stem } \\
\mathbf{a n g l e} \\
\left(\boldsymbol{\alpha}, \boldsymbol{\circ}^{\circ}\right.\end{array}$ & $\begin{array}{c}\text { Tan. force } \\
(\mathbf{N})\end{array}$ & $\begin{array}{c}\text { Time to } \\
\text { detach } \\
(\mathbf{s})\end{array}$ & $\begin{array}{c}\text { Cycles to } \\
\mathbf{d e t a c h} \\
(\mathbf{N u m})\end{array}$ & $\begin{array}{c}\text { Repeti- } \\
\text { tions } \\
(\mathbf{N u m})\end{array}$ \\
\hline Marisol & 60 & 4.7 & 7 & 66 & 53 & 7 & 2.37 & 11.1 & 4 \\
\hline Marisol & 60 & 9.5 & 11 & 87 & 112 & 7 & 1.34 & 12.7 & 5 \\
\hline Marisol & 60 & 13.6 & 9 & 65 & 73 & 7 & 0.33 & 4.3 & 5 \\
\hline Marisol & 180 & 3.1 & 10 & 87 & 83 & 11 & 0.54 & 1.67 & 4 \\
\hline Nova & 60 & 4.1 & 4.3 & 46 & 45 & 1.8 & 17.45 & 71.5 & 5 \\
\hline Nova & 60 & 9.3 & 6.0 & 58 & 125 & 4.0 & 6.18 & 57.5 & 6 \\
\hline Nova & 60 & 14.0 & 14.2 & 79 & 146 & 4.5 & 0.94 & 13.2 & 6 \\
\hline Nova & 100 & 4.1 & 9.6 & 101 & 102 & 3.2 & 3.94 & 16.2 & 6 \\
\hline Nova & 100 & 9.3 & 16.6 & 102 & 104 & 5.7 & 0.29 & 2.7 & 6 \\
\hline Nova & 100 & 14.0 & 9.0 & 85 & 119 & 7.9 & 0.30 & 4.2 & 6 \\
\hline Nova & 180 & 4.1 & 9.6 & 128 & 139 & 4.9 & 1.48 & 6.1 & 5 \\
\hline Valencia & 60 & 9.4 & 10 & 96 & 104 & 8 & 1.66 & 15.6 & 4 \\
\hline Valencia & 60 & 17.4 & 11 & 104 & 83 & 9 & 0.50 & 8.7 & 4 \\
\hline Valencia & 100 & 8.8 & 17 & 129 & 134 & 10 & 0.50 & 4.4 & 4 \\
\hline
\end{tabular}


Table 6. Parameters measured in the fruits for the different stroke and frequency applied to 'Nova' mandarins: translational force $(F)$, tangential force $(F t)$ and fruit-peduncle bending angle $(\alpha)$

\begin{tabular}{|c|c|c|c|c|c|c|c|c|c|c|c|c|}
\hline & \multicolumn{3}{|c|}{$F(\mathrm{~N})$} & \multicolumn{3}{|c|}{$\alpha\left(^{\circ}\right)$} & \multicolumn{3}{|c|}{$F t(\mathrm{~N})$} & \multicolumn{3}{|c|}{ Ratio $F / F t$} \\
\hline & $4.1 \mathrm{~Hz}$ & $9.3 \mathrm{~Hz}$ & $14.0 \mathrm{~Hz}$ & $4.1 \mathrm{~Hz}$ & $9.3 \mathrm{~Hz}$ & $14.0 \mathrm{~Hz}$ & $4.1 \mathrm{~Hz}$ & $9.3 \mathrm{~Hz}$ & $14.0 \mathrm{~Hz}$ & $\begin{array}{l}4.1 \\
\mathrm{~Hz}\end{array}$ & $9.3 \mathrm{~Hz}$ & $\begin{array}{r}14.0 \\
\mathrm{~Hz}\end{array}$ \\
\hline $60 \mathrm{~mm}$ & $4,3 \mathrm{aa}$ & $6.0 \mathrm{aa}$ & $14.2 \mathrm{ab}$ & 45 aа & $125 \mathrm{ab}$ & $146 \mathrm{ab}$ & $1.8 \mathrm{aa}$ & $4.0 \mathrm{ab}$ & $4.5 \mathrm{ab}$ & 2.4 & 1.5 & 3.2 \\
\hline $100 \mathrm{~mm}$ & 9,6 ba & $16.6 \mathrm{ba}$ & $9.0 \mathrm{aa}$ & $102 \mathrm{ba}$ & $104 \mathrm{aa}$ & $119 \mathrm{aa}$ & $3.2 \mathrm{aa}$ & $5.7 \mathrm{ab}$ & $7.9 \mathrm{bc}$ & 3.0 & 2.9 & 1.1 \\
\hline $180 \mathrm{~mm}$ & $9,6 \mathrm{~b}-$ & - & - & $139 \mathrm{~b}-$ & - & - & $4.9 \mathrm{~b}-$ & - & - & 2.0 & - & \\
\hline
\end{tabular}

